\title{
Inner tooth morphology of Homo erectus from Zhoukoudian. New evidence from an old collection housed at Uppsala University, Sweden
}

Clément Zanolli ${ }^{\mathrm{a}}$, Lei Pan ${ }^{\mathrm{b}, \mathrm{c}}$, Jean Dumoncel ${ }^{\mathrm{a}}$, Ottmar Kullmer ${ }^{\mathrm{d}, \mathrm{e}}$, Martin Kundrát ${ }^{\mathrm{f}}, \mathrm{Wu}$ Liu $^{\mathrm{b}}$,

Roberto Macchiarelli ${ }^{\mathrm{g}, \mathrm{h}}$, Lucia Mancini ${ }^{\mathrm{i}}$, Friedemann Schrenk ${ }^{\mathrm{d}, \mathrm{e}}$, ClaudioTuniz $\mathrm{z}^{\mathrm{j}, \mathrm{k}, \mathrm{l}}$

a

UMR 5288 CNRS, Université Toulouse III - Paul Sabatier, France

b

Key Laboratory of Vertebrate Evolution and Human Origins, Institute of Vertebrate

Paleontology and Paleoanthropology, CAS, Beijing, China

c

State Key Laboratory of Palaeobiology and Stratigraphy, Nanjing Institute of Geology and Palaeontology, CAS, Nanjing, China

d

Department of Palaeoanthropology, Senckenberg Research Institute, Frankfurt am Main, Germany

$\mathrm{e}$

Department of Paleobiology and Environment, Institute of Ecology, Evolution, and Diversity, Goethe University, Max-von-Laue-Str. 13, 60438 Frankfurt, Germany

$\mathrm{f}$

Center for Interdisciplinary Biosciences, Technology and Innovation Park, Pavol Jozef

Safarik University, Kosice, Slovak Republic

g

UMR 7194 CNRS, Muséum National d'Histoire Naturelle, Paris, France

h

Unité de Formation Géosciences, University of Poitiers, France

Elettra-Sincrotrone Trieste S.C.p.A., Basovizza (Trieste), Italy

j

Multidisciplinary Laboratory, The 'Abdus Salam' International Centre for Theoretical

Physics, Trieste, Italy 
Centro Fermi, Museo Storico della Fisica, Rome, Italy

Center for Archaeological Science, University of Wollongong, Australia

\begin{abstract}
Locality 1, in the Lower Cave of the Zhoukoudian cave complex, China, is one of the most important Middle Pleistocene paleoanthropological and archaeological sites worldwide, with the remains of c. 45 Homo erectus individuals, 98 mammalian taxa, and thousands of lithic tools recovered. Most of the material collected before World War II was lost. However, besides two postcranial elements rediscovered in China in 1951, four human permanent teeth from the 'Dragon Bone Hill,' collected by O. Zdansky between 1921 and 1923, were at the time brought to the Paleontological Institute of Uppsala University, Sweden, where they are still stored. This small sample consists of an upper canine (PMU 25719), an upper third molar (PMU M3550), a lower third premolar crown (PMU M3549), and a lower fourth premolar (PMU M3887). Some researchers have noted the existence of morpho-dimensional differences between the Zhoukoudian and the H. erectus dental assemblage from Sangiran, Java. However, compared to its chrono-geographical distribution, the Early to Middle Pleistocene dental material currently forming the Chinese-Indonesian $H$. erectus hypodigm is quantitatively meager and still poorly characterized for the extent of its endostructural variation. We used micro-focus X-ray tomography techniques of virtual imaging coupled with geometric morphometrics for comparatively investigating the endostructural conformation (tissue proportions, enamel thickness distribution, enamel-dentine junction morphology, pulp cavity shape) of the four specimens stored in Uppsala, all previously reported for their outer features. The results suggest the existence of time-related differences between continental and insular Southeast Asian dental assemblages, the Middle Pleistocene Chinese teeth apparently retaining an inner signature closer to the likely primitive condition represented by the Early Pleistocene remains from Java, while the Indonesian stock evolved toward tooth structural simplification.
\end{abstract}




\section{Introduction}

\subsection{The cave complex site of Zhoukoudian}

The karstic cave complex site of Zhoukoudian, approximately $42 \mathrm{~km}$ South of Beijing, China, is one of the historically most prolific and extensively investigated prehistoric sites in Asia (e.g., Black et al., 1933, Black, 1934, Weidenreich, 1937, Weidenreich, 1941, Weidenreich, 1943, Pei and Zhang, 1985, Wu et al., 1985, Zhou et al., 2000, Shen et al., 2001, Shen et al., 2009, Boaz et al., 2004, Gaboardi et al., 2005). Initial excavations were carried out by the paleontologist Otto Zdansky, who unearthed the first human remains of the so-called 'Dragon Bone Hill,' together with faunal material and lithic industry (Zdansky, 1926). Due to the large amount of material recovered at Locality 1, in the Lower Cave (c. 45 human individuals, 98 mammalian taxa, and thousands of lithic tools), Zhoukoudian is considered one of the most important Middle Pleistocene paleoanthropological and archaeological sites worldwide (Wood, 2015).

Zhoukoudian Locality 1 preserves an approximately $40 \mathrm{~m}$ thick sedimentary sequence that can be divided, from top to bottom, into 17 stratigraphic levels (Layers), the first top layer being the youngest (Wu et al., 1985; for a review of the stratigraphic sequence, see; Shen et al., 2009). Most of the human remains derive from Layers 8-9 and 3-4 (Yang et al., 1985). The Layers 8 and 9, representing an accumulation of c. $6 \mathrm{~m}$, are composed of limestone and dolomitic rockfall debris interbedded with fine silt/clay and sand (Goldberg et al., 2001). The c. $8 \mathrm{~m}$ thick Layers 3 and 4 show various facies: Layer 4 exhibits a succession of fine silts with some clay and sand rich in phytoliths mixed with ashes (with burnt bones suggesting the intentional use of fire; Binford and Ho, 1985, Weiner et al., 1998, Weiner et al., 1999, Zhang et al., 2014, Zhong et al., 2014; but see also Wu, 1999), whereas Layer 3 displays centimeter thick cemented beds and localized areas rich in circular voids (vesicles), indicating the presence of vegetation. These features indicate that conditions were becoming progressively wetter during the deposition of Layers 4 and 3, with various long-term openings of the cave (Goldberg et al., 2001). Based on multiple relative (biostratigraphy, paleomagnetism) and absolute (fission track, thermoluminescence, ESR, ${ }^{230} \mathrm{Th} /{ }^{234} \mathrm{U}$ and U-series) dating methods, Layers 8-9 were first estimated to c. 350-500 ka (Zhao et al., 1985, Huang et al., 1993), whereas Layers 3-4 were estimated to c. 250-350 ka (Yuan and Chen, 1980, Pei, 1985, Zhao et al., 1985, Guo et al., 1991, Huang et al., 1993, Grün et al., 1997). More recent analyses based on cosmogenic ${ }^{26} \mathrm{Al} /{ }^{10} \mathrm{Be}$ burial dating of quartz sediments and artifacts from the lower strata of Locality 1 yielded ages 
between 0.68 and $0.78 \mathrm{Ma}$ ago, compatible with the Chinese loess stratigraphy S6_S7 levels and with the MIS 17-19 stages (Shen et al., 2009). These dates, older than previous estimates, indicate that a human presence at northern China latitudes occurred under different climatic and environmental conditions, even during the relatively mild glacial period corresponding to MIS 18 (Shen et al., 2009).

The mammalian assemblages from Layers 8-9 support such interpretation, with a cold-climate fauna suggesting steppe and forest environments and a trend over time toward increasing grasslands, even though warmer climatic conditions prevailed during the deposition of Layer 5 (Shen et al., 2009). Oxygen isotope data from herbivorous teeth from Layers 8-9 and Layer 4 indicate a habitat of mixed $\mathrm{C}_{3} / \mathrm{C}_{4}$ vegetation and winter monsoon strengthening during the colder, drier intervals (Gaboardi et al., 2005).

The faunal record from Zhoukoudian Locality 1 is rich in invertebrates (fluvial and terrestrial gastropods; Black, 1933), amphibians (at least two anuran taxa; Black, 1933), reptiles (including squamate taxa belonging to Ophidia and Lacertilia, as well as testudines; Black, 1933), and birds (represented by a rich avifauna, including large flightless birds like Struthio sp.; Black, 1934, Rich et al., 1986). The mammal fauna is represented by a few Early Pleistocene survivors (like Equus sanmeniensis, Sus lydekkeri or Paracamelus gigas), as well as by a number of taxa recorded for the first time at the regional scale (such as Myospalax, Ursus spelaeus, Vulpes vulpes, Crocuta ultima, Cervus canadensis; Lucas, 2001, Li et al., 2014). In this respect, it has been estimated that $89 \%$ of the fossil taxa represented in this locality are still living today (Lucas, 2001).

Also, the hominin-bearing Layers 8-9 recorded a diversity of large mammals, including nonhuman primates (Macaca robustus), Carnivora (Canis lupus, Ursus thibetanus, Ursus arctos), Perissodactyla (Dicerorhinus choukoutienensis, Coelodonta antiquitatis, E. sanmeniensis), Artiodactyla (Moschus moschiferus, Megaceros pachyosteus, Ovis sp., Bison sp.), and Proboscidea (Palaeoloxodon cf. namadicus), as well as micromammal taxa belonging to Chiroptera (Rhinolophus, Miniopterus, Ia), Lagomorpha (Ochotona), Rodentia (Cricetinus, Cricetulus, Micromys, Rattus, Gerbillus, Microtus), and Soricomorpha (Scaptochirus, Neomys, Crocidura; Hu, 1985, Lin, 1985, Yang et al., 1985, Li et al., 2014).

A similar faunal spectrum is found in Layers 3-4, which also contains some additional taxa (notably, Carnivora like Canis cyonids, Nyctereutes sinensis, Cuon antiquus, Vulpes cf. corsac, 
Meles cf. leucurus, Gulo sp., Pachycrocuta brevirostris, Machairodus inexpectatus, Panthera cf. tigris, Panthera cf. pardus, Felis teilhardi, Felis cf. microtis, but also Artiodactyla like Cervus cf. nippon, Spirocerus peii, Bubalus teilhardi, and Rodentia such as Trogontherium cuvieri and Hystrix cf. subcristata; Hu, 1985, Lin, 1985, Yang et al., 1985, Li et al., 2014). Considering that the majority of these mammals are accustomed to warm-mild climate open grassland, but that some are woodland-associated taxa, the paleoenvironmental and paleoecological signals point to the presence of both expanded steppe and temperate forest during the human occupation phases (Li et al., 2014).

Over 17,000 stone artifacts were recovered in most of the stratigraphic levels of Locality 1, from Layer 11 to 1 (Pei and Zhang, 1985, Wu et al., 1985). Among those, nearly half were classified into 10 morphological categories, where flakes, choppers, core-tools, scrapers, points, and burins are the most abundant (Shen et al., 2016). The assemblage from Layers 4-5 is the largest one. The amount of large size tools tends to decrease from Layers 8-10 to 1-5, while the opposite is true for the flakes and the pointed tools (Wu et al., 1985, Shen et al., 2016). In most layers, the most abundant raw material is quartzite (representing up to $95.8 \%$ of the lithic artifacts in Layers 4-5; Li, 2016), a material anyhow not found in the vicinity of the Zhoukoudian area (Pei and Zhang, 1985); on the other hand, the local raw materials, like chert, were mostly exploited during the deposition of Layers 1-5 (Shen et al., 2016).

\subsection{Human remains from Locality 1 and the tooth specimens stored at Uppsala University}

Zhoukoudian Locality 1 yielded all of the early Middle Pleistocene human remains of the

'Dragon Bone Hill.' Taphonomic analyses show that $67 \%$ of such remains exhibit large carnivore bite marks and high bone fragmentation patterns compatible with the activity recorded for the large Pleistocene cave hyena, P. brevirostris (Ciochon et al., 2000, Boaz et al., 2000, Boaz et al., 2004). Overall, the contextual evidence from the fossil assemblages, the carnivore damage on the bone remains, and the anthropic activity patterns at Zhoukoudian Locality 1 support a scenario of sporadic phases of human occupation, when the cave was not a hyena den (Boaz et al., 2004). Between 1921 and 1923, four isolated permanent teeth were recovered by O. Zdansky and then brought to the Paleontological Institute of Uppsala University, Sweden: an upper canine, an upper molar, and two lower premolars. One premolar (PMU M3549) and the molar tooth (PMU M3550) were described by Zdansky (1926) and by Black (1927) and attributed to Sinanthropus 
pekinensis; the second premolar (PMU M3887) was reported later on by Zdansky (1952) and attributed to the same taxon. In the meantime, the still unreported canine tooth (PMU 25719) turned up within the faunal remains, where it was recovered only in 2011 and described by Kundrát et al. (2015).

From 1927 to 1966, continuing research at the site yielded nearly 200 Middle Pleistocene human remains, representing up to 45 individuals (Wood, 2015). Under still unknown circumstances, most of the material collected before World War II was lost (Berger et al., 2012), and only two postcranial elements (a tibial and a femoral fragment rediscovered in China in 1951; Wang and Sun, 2000) and the four isolated teeth stored in Uppsala currently represent the pre-WWII human fossil assemblage from the 'Dragon Bone Hill.' Later excavations at Zhoukoudian Locality 1 recovered additional human fossils and faunal and cultural materials (Wood, 2011).

The human remains from Zhoukoudian Locality 1 are now generally regarded as classic representatives of Homo erectus (Antón, 2003, Antón, 2013, Wood, 2011, Wood, 2015). Interestingly, some researchers noted that the cranial assemblage from Zhoukoudian resembles the Sambungmacan/Ngandong series, but differs markedly from the Trinil and Sangiran material (Schwartz and Tattersall, 2003). In addition, the existence of morphological and dimensional differences between the Zhoukoudian and the Early-Middle Pleistocene Sangiran dental samples have also been pointed out (Kaifu et al., 2005b, Xing et al., 2014).

\subsection{Goals of the study}

Compared to its chrono-geographical distribution, the Early to Middle Pleistocene dental material currently forming the Chinese-Indonesian $H$. erectus hypodigm is quantitatively meager and still poorly characterized for the extent of its endostructural variation (Smith et al., 2009, Zanolli, 2011, Zanolli, 2015, Liu et al., 2013, Liu et al., 2017, Xing et al., 2014, Xing et al., 2016, Martinón-Torres et al., 2017).

Information on the external morphology and crown size of the four teeth stored in Uppsala have been provided in previous contributions (Zdansky, 1926, Zdansky, 1952, Black, 1927, Kundrát et al., 2015). Given the potential value in taxonomic, phylogenetic, and adaptive/evolutionary studies of quantitative data on the inner tooth structural organization (e.g., Macchiarelli et al., 2006, Macchiarelli et al., 2008, Olejniczak et al., 2008a, Olejniczak et al., 2008b, Skinner et al., 2008a, Skinner et al., 2008b, Bayle et al., 2010, Bailey et al., 2011, Martínez de Pinillos et al., 
2014, Martinón-Torres et al., 2014, Zanolli et al., 2014, Zanolli et al., 2015, Pan et al., 2017), we used micro-focus X-ray tomography techniques of virtual imaging coupled with geometric morphometrics for comparatively investigating their tissue proportions, enamel thickness distribution, enamel-dentine junction morphology, and pulp cavity shape. When testable, we examined the specimens from Zhoukoudian Locality 1 under the assumption that their endostructural signature is closer to that of the Chinese (Liu et al., 2013, Liu et al., 2017, Xing et al., 2014, Xing et al., 2016), rather than the Indonesian, fossil assemblage (Smith et al., 2009, Zanolli, 2011, Zanolli, 2015, Kaifu et al., 2015).

\section{Materials and methods}

The four tooth specimens from Zhoukoudian Locality 1 permanently stored at the Paleontological Institute of Uppsala University represent: a complete upper right canine (URC: PMU 25719), a complete upper right third molar (URM3: PMU M3550), a lower left third premolar crown (LLP3: PMU M3549), and a nearly complete lower right fourth premolar, only damaged on its distobuccal root (LRP4: PMU M3887; Kundrát et al., 2015; Fig. 1). 


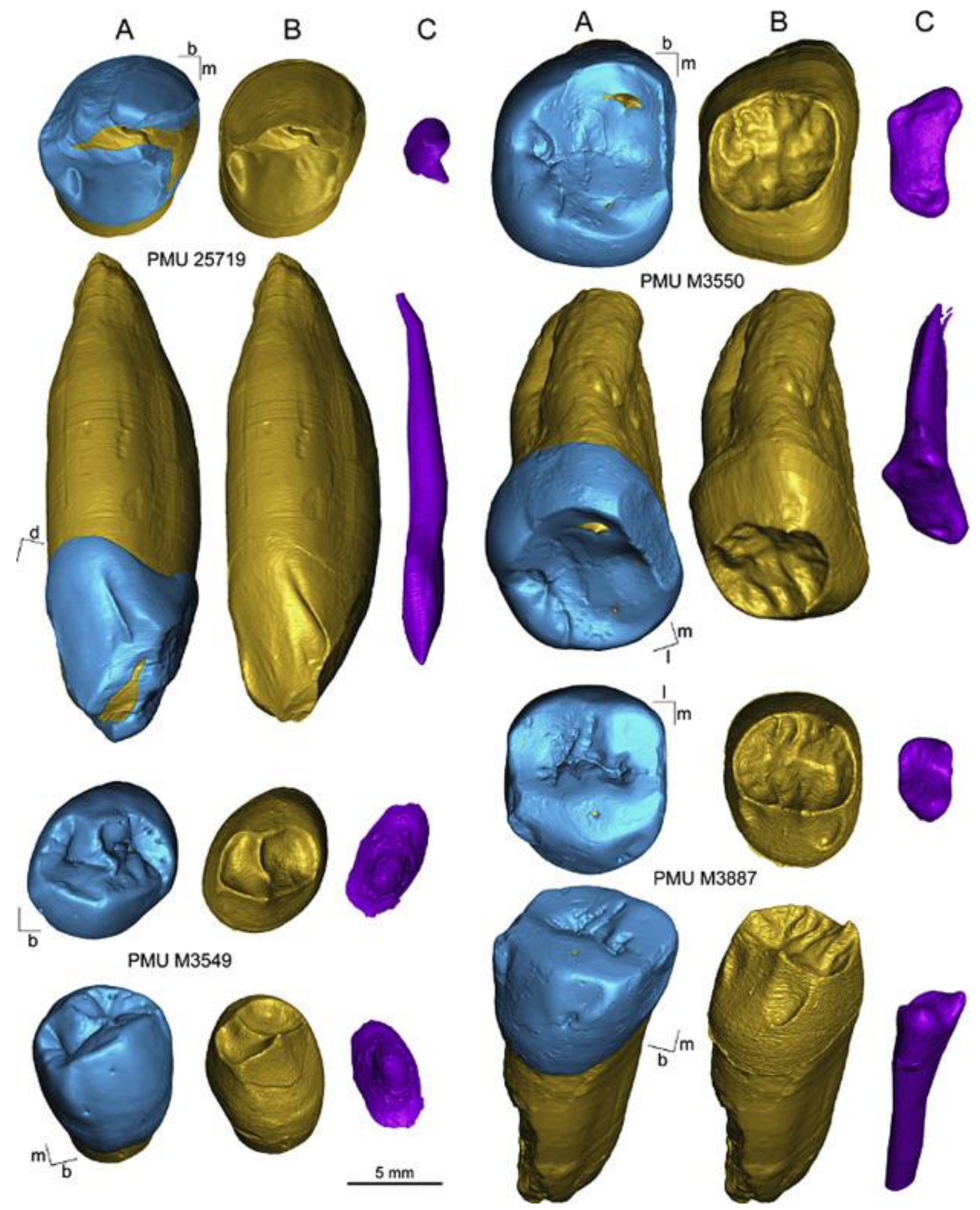

Figure 1. Virtual rendering of the four Homo erectus specimens from Zhoukoudian. PMU 25719, upper right canine; PMU M3550, upper right third molar; PMU M3549, lower left third premolar crown; PMU M3887, lower right fourth premolar. For each specimen, the 
outer surface (A), the dentine (B), and the pulp cavity (C) are illustrated in occlusal and occluso-lateral views. Scale bar $=5.0 \mathrm{~mm}$.

The specimens were imaged by X-ray computed microtomography $(\mu \mathrm{CT})$ at the Multidisciplinary Laboratory of the ICTP, Trieste (Tuniz et al., 2013), according to the following parameters: 110 $\mathrm{kV}$ voltage, $90 \mu \mathrm{A}$ current, angular step of $0.25^{\circ}$ over a scan angle of $360^{\circ}$. The final volumes were reconstructed with an isotropic voxel size ranging from 6.4 to $11.6 \mu \mathrm{m}$.

Using the commercial software Avizo v.8.0 (Visualization Sciences Group Inc.) and the freeware ImageJ (Schneider et al., 2012), a semi-automatic, threshold-based segmentation was carried out following the half-maximum height (HMH) method (Spoor et al., 1993) and the region of interest thresholding protocol (ROI-Tb; Fajardo et al., 2002) by taking repeated measurements on different slices of the virtual stack (Coleman and Colbert, 2007).

Among the four Chinese specimens, only the lower third premolar (PMU M3549) is unworn and suitable for the assessment of whole crown tissue proportions, the other specimens showing variably extended occlusal wear facets and dentine exposure (stage 2-3 following Smith [1984]). The plane halfway between that containing the most apical continuous ring of enamel and that containing the most apical enamel was taken as the cervical plane (Olejniczak et al., 2008a). The tooth's crown was virtually separated from the roots and the following variables measured or calculated: Ve, the volume of the enamel cap $\left(\mathrm{mm}^{3}\right)$; Vcdp, the volume of the coronal dentine, including the coronal aspect of the pulp chamber $\left(\mathrm{mm}^{3}\right)$; Vc, the total crown volume, including enamel, dentine, and pulp $\left(\mathrm{mm}^{3}\right)$; SEDJ, the enamel-dentine junction (EDJ) surface $\left(\mathrm{mm}^{2}\right)$; $\mathrm{Vcdp} / \mathrm{Vc}(=100 * \mathrm{Vcdp} / \mathrm{Vc})$, the percent of coronal volume that is dentine and pulp (\%); 3D AET (=Ve/SEDJ), the three-dimensional (3D) average enamel thickness (mm); 3D RET (=100*3D $\mathrm{AET} /\left[\mathrm{Vcdp}^{1 / 3}\right]$ ), the scale-free 3D relative enamel thickness (see Kono, 2004, Olejniczak et al., 2008a). As no directly comparable data on crown tissue proportions are so far available for Pleistocene human LP3s from continental and insular Southeast Asia, we compared the results of PMU M3549 to: the Early Pleistocene early Homo specimen SKX 21204 from Swartkrans, South Africa (Pan et al., 2016); four Neanderthal teeth from Krapina, Croatia (KRD33, KRD34, KRD111, KRD114; NESPOS Database, 2017); and 10 recent human LP3s from Europe and Africa (original data). 
Given the availability in the $H$. erectus assemblage from Java of two upper third molars (the specimens NG0802.1 [Zanolli, 2011, Zanolli, 2015] and Sangiran 4 [original data]), in order to extract the maximum amount of structural information from the occlusally worn Chinese specimen, we assessed and compared its lateral (non-occlusal) enamel distribution pattern. In fact, while occlusal enamel topography is more directly informative in terms of functional activity and adaptive responses (e.g., Kono, 2004, Kono and Suwa, 2008, Olejniczak et al., 2008b, Guy et al., 2013), lateral enamel thickness is also involved in dissipating occlusally related stresses (Benazzi et al., 2013a, Benazzi et al., 2013b). Accordingly, a plane parallel to the cervical one and tangent to the lowest enamel point of the occlusal basin was established, all material above it was removed, and only the enamel and dentine portions between these two planes was preserved to estimate tissue proportions (Toussaint et al., 2010, Macchiarelli et al., 2013, Zanolli et al., 2017). By using a recently developed analytical protocol (Zanolli et al., 2017), the following variables were measured or calculated on the new set of virtually reduced and simplified M3 crowns: LVe, the lateral volume of enamel $\left(\mathrm{mm}^{3}\right)$; LVcdp, the lateral volume of coronal dentine, including the lateral coronal aspect of the pulp chamber $\left(\mathrm{mm}^{3}\right)$; LSEDJ, the enamel-dentine junction lateral surface $\left(\mathrm{mm}^{2}\right)$; 3D LAET (=LVe/LSEDJ), the 3D lateral average enamel thickness $(\mathrm{mm}) ; 3 \mathrm{D} \mathrm{LRET}\left(=100 * 3 \mathrm{D} \mathrm{LAET} /\left[\mathrm{LVcdp}^{1 / 3}\right]\right)$, the 3D lateral relative enamel thickness (Zanolli et al., 2017).

To visualize similarities versus differences in enamel thickness topography, ad hoc imaging techniques were used to virtually unroll the lateral enamel and to project it into standardized morphometric maps (Bondioli et al., 2010, Macchiarelli et al., 2013, Zanolli et al., 2017). By using a custom developed routine in R v.3.4.0 (R Development Core Team, 2017) with the packages spatstat (Baddeley et al., 2015) and gstat (Pebesma, 2004), enamel thickness values were standardized between 0 and 1 and each morphometric map was set within a grid of 40 columns and 180 rows. For the two Javanese $H$. erectus specimens, five Neanderthal UM3s from Krapina (KRD97, KRD109, KRD162, KRD163, KRD170; NESPOS Database, 2017), and five recent humans (original data), we produced a consensus map generated by merging the available individual records into a single dataset and by subsequently calculating the interpolation using Generalized Additive Modeling (GAM; see Bondioli et al., 2010).

Intra- and inter-observer tests for accuracy of the estimates were run by two observers. Linear, surface, and volumetric measurements provided differences less than $4 \%$ for both tests. 
Description of the nonmetric features at the enamel-dentine junction (EDJ) is adapted from classical outer crown features scored following Scott and Turner (1997) and the scores of the Arizona State University Dental Anthropology System (ASUDAS; Turner et al., 1991).

Geometric morphometric (GM) analysis of the EDJ was performed on the virtual surfaces of all four specimens from Zhoukoudian. The slightly worn dentine apex of the canine tooth (PMU 25719) and that of the upper M3 paracone (PMU M3550) were partially reconstructed (by elaborating a 3D approach deriving from Smith et al., 2012). Except for the canine that lacks adequate homologous points, a landmark-based analysis was thus performed by placing one landmark on the apex of each main cusp (the paracone, protocone, metacone, and hypocone of the UM3 and the protoconid and metaconid of the two premolars). A set of sliding semilandmarks were then positioned along the marginal and oblique/transversal crests (82 semilandmarks on the UM3 and 72 semilandmarks on the P3 and P4; see Pan et al., 2016). In addition, a recently developed landmark-free approach was applied to compare the EDJ conformation (for its application to cercopithecoid molars, see Beaudet et al., 2016). This method relies on the construction of group-average surface models and their deformation to the investigated surfaces (Durrleman et al., 2012a, Durrleman et al., 2012b, Dumoncel et al., 2014). The surfaces are represented by a set of oriented faces and the comparison does not assume a point-to-point correspondence between samples, as in classical landmark-based GM analyses. As a pre-processing step, unscaled EDJs were aligned, using the "Align Surface" module available on the software Avizo v.8.0. The deformations between surfaces were mathematically modeled as a diffeomorphism, i.e., a one-to-one deformation of the 3D space that is smooth, invertible, and with a smooth inverse, which is particularly appropriate for comparing overall shapes and local orientation in the field of computational anatomy (Glaunès and Joshi, 2006, Durrleman et al., 2014). From a set of surfaces, together with a set of initial control points located near its most variable parts, a mean shape and a set of momenta parameterizing the deformations of the mean shape to each individual were estimated (Durrleman et al., 2012a, Durrleman et al., 2012b). Using the package Morpho v.2.5.1 (Schlager, 2017) for R v.3.4.0 (R Development Core Team, 2017), a generalized Procrustes analysis (GPA) and a weighted between-group principal component analysis (bgPCA) based on the Procrustes and deformation-based shape residuals (Mitteroecker and Bookstein, 2011) were performed. Allometry was tested on the landmarkbased analyses using the coefficient of determination (R2) of a multiple regression (Bookstein, 
1991), in which the explicative variable is the centroid size and the dependent variables are the bgPC scores (Mitteroecker et al., 2013).

\section{Results}

\subsection{Tooth tissue proportions and enamel thickness}

Tissue proportions assessed for the lower third premolar PMU M3549 and, limitedly to the lateral crown, for the upper third molar PMU M3550 are shown in Table 1 and illustrated in Figure 2, together with the estimates from some Pleistocene and extant human specimens/samples (see also Supplementary Online Material [SOM] Table S1).

Table 1. Tooth crown tissue proportions (percent of coronal volume that is dentine and pulp, Vcdp/VC) and 3D relative enamel thickness (RET) assessed in the Homo erectus lower third premolar PMU M3549 and upper third molar PMU M3550 from Zhoukoudian and compared to the estimates from some fossil and extant human specimen/samples.

\section{Specimen/sample}

PMU M3549

$\operatorname{EHSA}(n=1)$

$\operatorname{NEA}(n=4)$

$\mathrm{RH}(n=10)$
Mean

Range

Mean

Range
Vedp/Vc (\%)

48.2

41.4

56.4

$53.3-58.1$

47.5

$42.7-52.2$

LVcdp/LVc (\%)

77.5

75.6

74.0-77.1

79.6
3D RET

15.6

14.4-18.3

24.0

19.4-28.3
PMU M3550

HEJ $(n=2)$

$\operatorname{NEA}(n=5)$
Mean

Range

Mean

\section{D LRET}

11.8

11.9-12.5

9.6 
Specimen/sample

$\begin{array}{llll} & \text { Range } & 76.4-85.6 & 6.3-11.4 \\ \mathrm{RH}(n=5) & \text { Mean } & 77.2 & 11.3 \\ & \text { Range } & 73.5-79.8 & 10.4-13.3\end{array}$

a

Because of occlusal wear in PMU M3550, in all UM3s the variables have been assessed on the virtually cropped crowns (lateral Vcdp/VC and 3D LRET). EHSA = early Homo from South Africa (specimen SKX 21204 from Swartkrans), HEJ = Homo erectus from Java (specimens NG0802.1 and Sangiran 4 from Sangiran), NEA = Neanderthals (Krapina), RH = recent humans. See SOM Table S1 for the parameters used to compute $\mathrm{Vcdp} / \mathrm{VC}$ and 3D RET indices.
3D RET

3



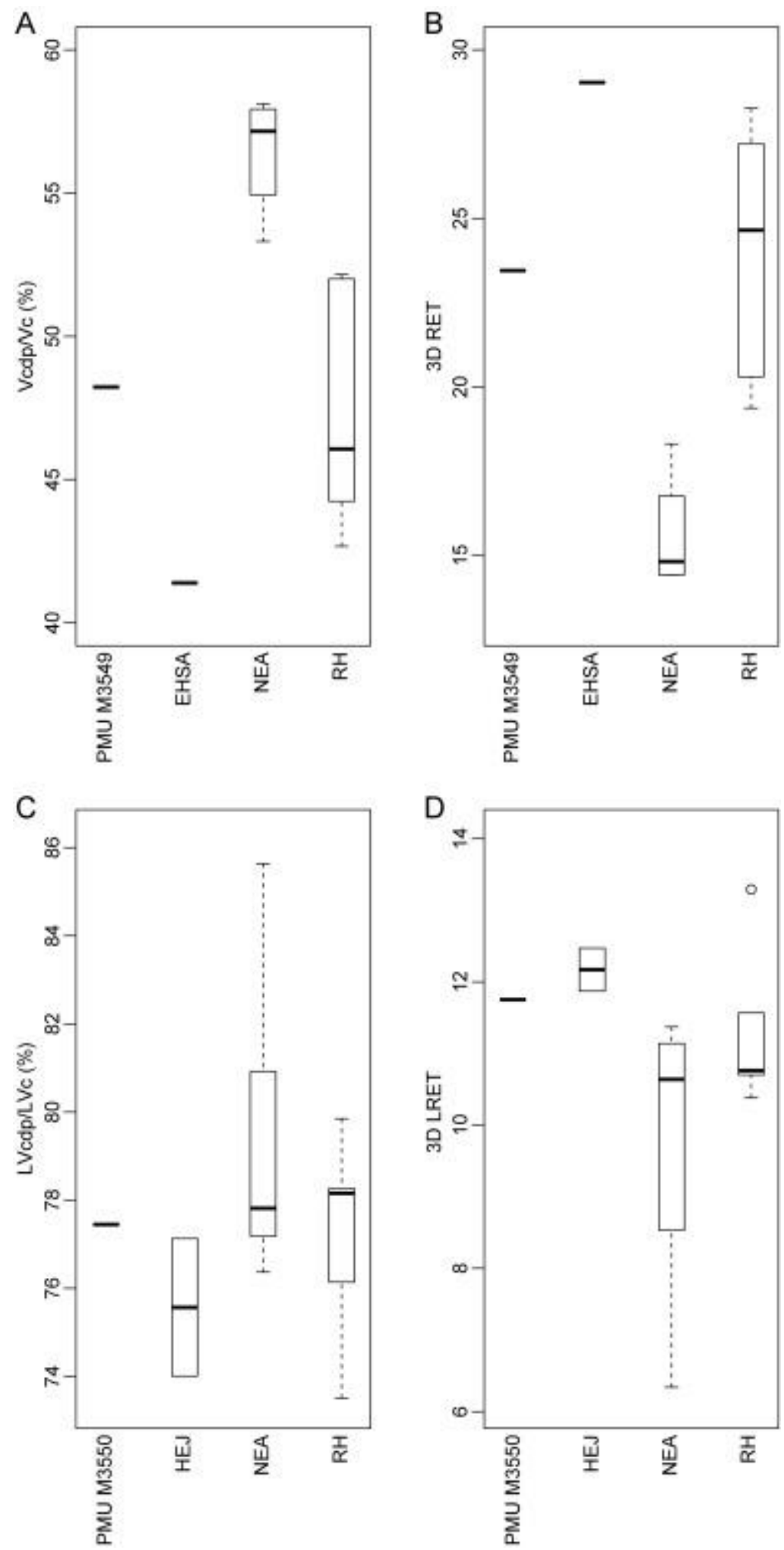

Figure 2. Tooth crown tissue proportions and enamel thickness assessed in the Homo erectus lower third premolar PMU M3549 and upper third molar PMU M3550 from Zhoukoudian, and compared to the estimates from some fossil and extant human 
specimen/samples (see Table 1). (A) Percent of crown dentine (Vcdp/Vc) in LP3s. (B) 3D relative enamel thickness (3D RET) in LP3s. (C) Percent of lateral crown dentine (LVcdp/LVc) in UM3s. (D) 3D lateral relative enamel thickness (3D RET) in UM3s. EHSA = early Homo from South Africa (SKX 21204 from Swartkrans), HEJ = Homo erectus from Java (NG0802.1 and Sangiran 4 from Sangiran), NEA = Neanderthals (Krapina; $n=4$ in $\mathrm{A}$ and $\mathrm{B} ; n=5$ in $\mathrm{C}$ and $\mathrm{D}), \mathrm{RH}=$ recent humans $(n=10$ in $\mathrm{A}$ and $\mathrm{B} ; n$ $=5$ in $\mathrm{C}$ and $\mathrm{D})$.

With its moderately low percent of crown dentine and pulp and relatively thick enamel, the premolar from Zhoukoudian falls within the range of variation shown by our comparative extant human sample. PMU M3549 displays higher Vcdp/Vc and lower 3D RET values than measured in the SKX 21204 early Homo specimen from Swartkrans (Pan et al., 2016), while the opposite is observed with respect to the Neanderthal estimates (Fig. 2).

Comparative enamel crown topographic variation for this Chinese premolar is revealed by the cartographies imaged in Figure 3, which map topographic thickness variations at the outer enamel surface. Similar to the pattern shown by all lower P3s considered in the study, the thickest enamel in the specimen from Zhoukoudian is found on the upper mid-crown (occlusal) portion of its buccal aspect but, compared to the Neanderthal and extant human conditions, also along the mesial and distal margins. In the thickly enameled early Homo specimen from Swartkrans, which presents the highest RET value for the lateral crown, enamel is more homogeneously distributed, but an extended thicker spot is uniquely found at its distal cusp. In the relatively and absolutely thinner Neanderthal LP3s, thicker enamel is limited to the buccal aspect (Fig. 3). 

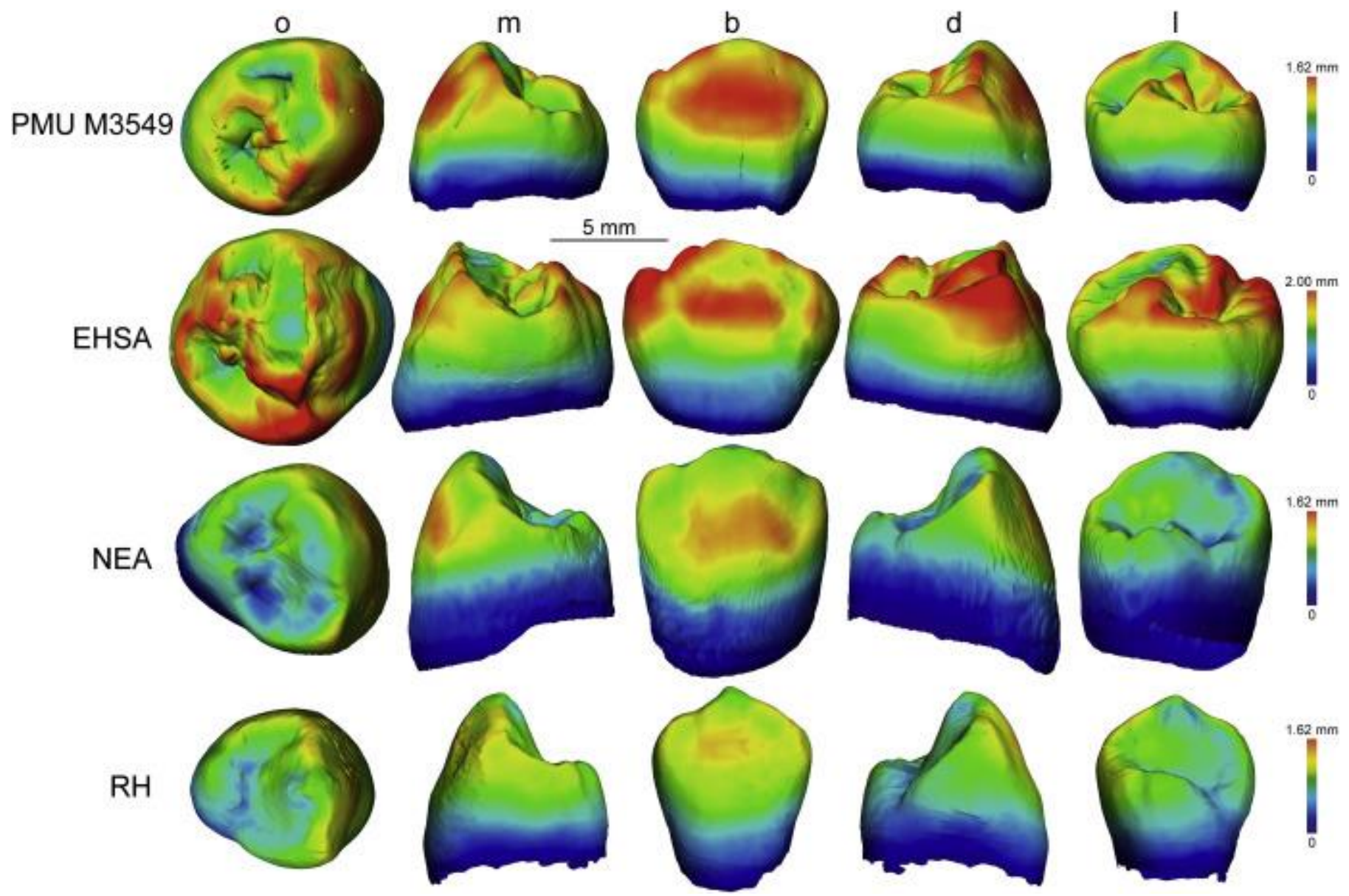

Figure 3. Enamel thickness cartographies of the Homo erectus lower third premolar PMU

M3549 from Zhoukoudian compared with those of some fossil and extant human LP3s.

Topographic thickness variation is rendered by a pseudo-color scale ranging from thinner dark-blue to thicker red. Independently from their original side, all crowns are shown as right. EHSA = early Homo from South Africa (SKX 21204 from Swartkrans), NEA = Neanderthals (Krapina; consensus map; $n=4$ ), $\mathrm{RH}=$ recent humans (consensus map; $n=$ 10), $\mathrm{o}=$ occlusal, $\mathrm{m}=$ mesial, $\mathrm{b}=$ buccal, $\mathrm{d}=$ distal, $\mathrm{l}=$ lingual. Scale bar $=1.62 \mathrm{~mm}$ in PMU M3549, NEA, and RH; scale bar $=2.0 \mathrm{~mm}$ in EHSA.

For the lateral crown aspect, the LVcdp/LVc percent ratio of the upper third molar PMU M3550 is indistinguishable from the Neanderthal and extant human estimates, but slightly exceeds that calculated for the two H. erectus specimens from Sangiran (Table 1; Fig. 2), the latter crowns again displaying thicker enamel (3D LRET). The standardized morphometric maps (MMs) of the 
virtually unrolled and projected lateral enamel of the Chinese specimen and the consensus MMs obtained for Javanese $H$. erectus, Neanderthals, and recent humans are shown in Figure 4.

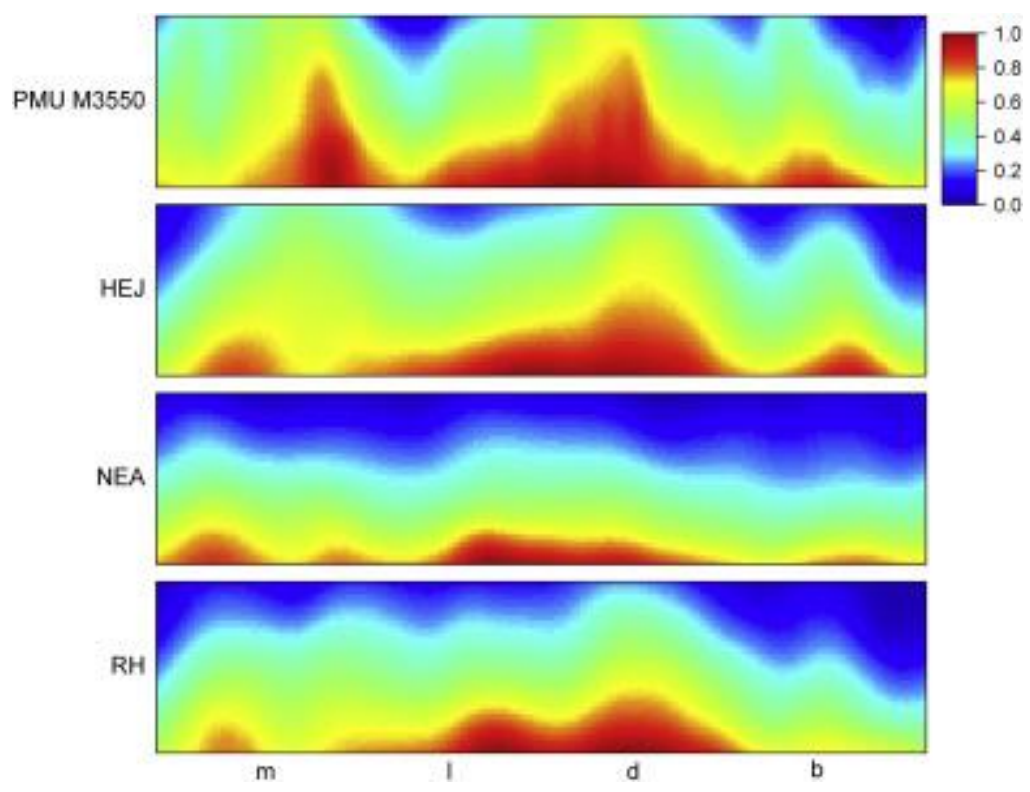

Figure 4. Enamel thickness cartography of the lateral enamel thickness in the Homo erectus upper third molar PMU M3550 from Zhoukoudian compared with the standardized morphometric maps (MMs) of some fossil and extant human UM3s.

Topographic thickness variation is rendered by a pseudo-color scale ranging from thinner dark blue to thicker red. HEJ = Homo erectus from Java (NG0802.1 and Sangiran 4 from Sangiran; consensus map), NEA = Neanderthals (Krapina; consensus map; $n=5), \mathrm{RH}=$ recent humans (consensus map; $n=5$ ), $\mathrm{m}=$ mesial, $\mathrm{l}=$ lingual, $\mathrm{d}=$ distal, $\mathrm{b}=$ buccal.

While displaying slightly thinner lateral enamel compared to the two crowns from Sangiran (Table 1), enamel thickness topographic distribution in PMU M3550 casts the pattern of the Javanese $H$. erectus representatives, the distolingual aspect revealing an extended thicker band well-projected cervically (Fig. 4). Also, likely associated with a shared tooth crown architecture (notably, outer surface convexity and intercuspal groove depth and extension), a distinct subocclusal thickening of the buccal compartment is present in both Chinese and Javanese specimens, while it ranges from faint to absent in Neanderthals and extant humans, whose crown maps are longitudinally much less contrasted. A distinct feature in PMU M3550 is represented by a triangular-shaped enamel thickening projecting deep into the mesial compartment (Fig. 4). 


\subsection{EDJ morphology and pulp cavity shape}

The EDJ of the upper canine PMU 25719 shows marked distal crests on both labial and lingual aspects (distal accessory ridge equivalent to ASUDAS grade 3), while the mesial marginal crest is less developed (despite the adjacent enamel breakage, its morphology is still preserved). Subtle digitations (nearly parallel and variably marked crests) are present on the lingual aspect. The pulp cavity displays a sub-circular cross-section along most of its height and a sub-conical shape at crown level (Fig. 1).

In the UM3 PMU M3550, the EDJ shows four main cusps (the dentine horn of the hypocone being quite blunt, comparable to ASUDAS grade 2), a low and interrupted transverse crest (with bifurcated paracone segments), a low and incomplete oblique crest (starting distally to the protocone dentine horn), and a number of accessory crests running from the marginal ridges toward the center of the occlusal basin (Fig. 1). There is no evidence of Carabelli's trait, as the lingual surface of the protocone is smooth (grade 0, following Ortiz et al. [2012] and ASUDAS). On a comparative basis, the morphology of its pulp chamber is peculiar. It exhibits a relatively flat roof bearing a sub-circular shallow cavity set at the center of the protocone horn and a single taurodontic and mesiodistally flattened root canal (Figure 1, Figure 5), while the Javanese $H$. erectus specimen Sangiran 4, from the Early Pleistocene Pucangan Formation of the Sangiran Dome, and all recent human UM3s examined in this study display more developed pulp horns and two to three splayed main root canals (Fig. 5). The specimen KRD 58 from Krapina, also imaged in Figure 5, shows the unique Neanderthal morphology (Macchiarelli et al., 2006, Kupczik and Hublin, 2010), with very high pulp horns corresponding to the three main cusps, but a single columnar pulp canal that only divides into three branches in its apical part (Fig. 5). 


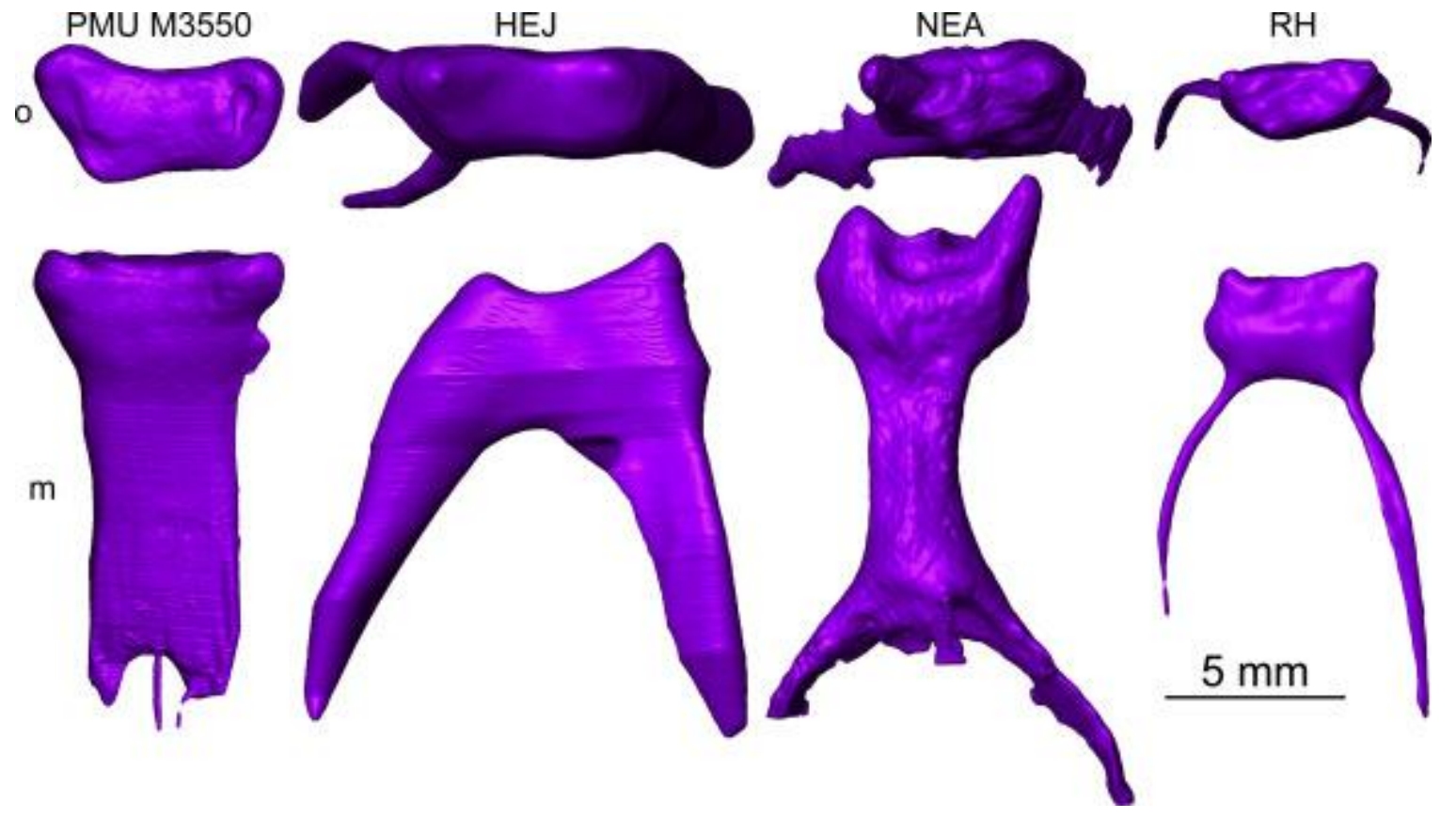

Figure 5. Virtual rendering of the pulp cavity of the Homo erectus upper third molar PMU M3550 from Zhoukoudian compared with that of some selected fossil and extant human UM3s. Independently from their original side, all specimens are shown as right. HEJ = Homo erectus from Java (Sangiran 4), NEA = Neanderthal (KRD58 from Krapina), RH = recent human, $\mathrm{o}=$ occlusal, $\mathrm{m}=$ mesial. Scale bar $=5.0 \mathrm{~mm}$.

To the best of our knowledge, no comparable information on the pulp cavity shape is available for Chinese H. erectus UM3s. However, that of a Middle Pleistocene lower M3 (PA834-2) from Longtan Cave, Hexian, is described as bearing five horns that correspond to each of the five main cusps (Xing et al., 2014). This morphology is also found in the LM2 and LM3 of the PA831 mandible from the same site, where the two mesial horns are higher than the three distal ones (Liu et al., 2017).

The unworn LP3 crown PMU M3549 displays two well-developed buccal and lingual dentine horns (ASUDAS grade 0). Its EDJ also expresses a complete transverse crest, an accessory cuspulid on the mesial marginal ridge, and a low accessory crest running from the distobuccal marginal ridge toward the center of the posterior fovea (Fig. 1). The pulp chamber, still in development, only displays a sub-conic rounded roof (Fig. 1).

Finally, the EDJ of the molarized LP4 PMU M3887 exhibits two well-developed mesial dentine horns and two smaller but distinct distal dentine horns corresponding to the hypoconid and 
entoconid, respectively; a small relief on the distal marginal ridge comparable to a minute hypoconulid, a bifurcated (with middle and distal segments) interrupted trigonid transversal crest, multiple talonid accessory crests running from the marginal ridges toward the center of the occlusal basin, and a protostylid-like feature visible as two mesial and distal grooves bordered by low crests on the buccal aspect (Fig. 1). Its pulp chamber only shows two developed horns corresponding to the mesial cusps, together with a thick columnar root canal (Fig. 1).

\subsection{GM analysis of the EDJ conformation}

The results of the between-group PCA (bgPCA) from the GM analyses of the EDJ using semilandmarks and the deformation-based method (see Materials and methods) are shown in Figure 6. For the landmark-based analyses (Fig. 6A-C), the first two components (bgPC1 and bgPC2) respectively show a moderate allometric signal ( $\mathrm{R}^{2}$ ranging from 0.17 to 0.44$)$ and no size-dependent shape variation $\left(\mathrm{R}^{2}\right.$ systematically $\left.<0.00\right)$, thus mostly representing shape variation. Overall, both landmark-based (Fig. 6A-C) and deformation-based (Fig. 6D-G) analyses distinguish between fossil and extant humans and give comparable results regarding the condition of the Chinese $H$. erectus teeth with respect to the Pleistocene and recent human specimens/samples considered in the analysis (Table 2). 

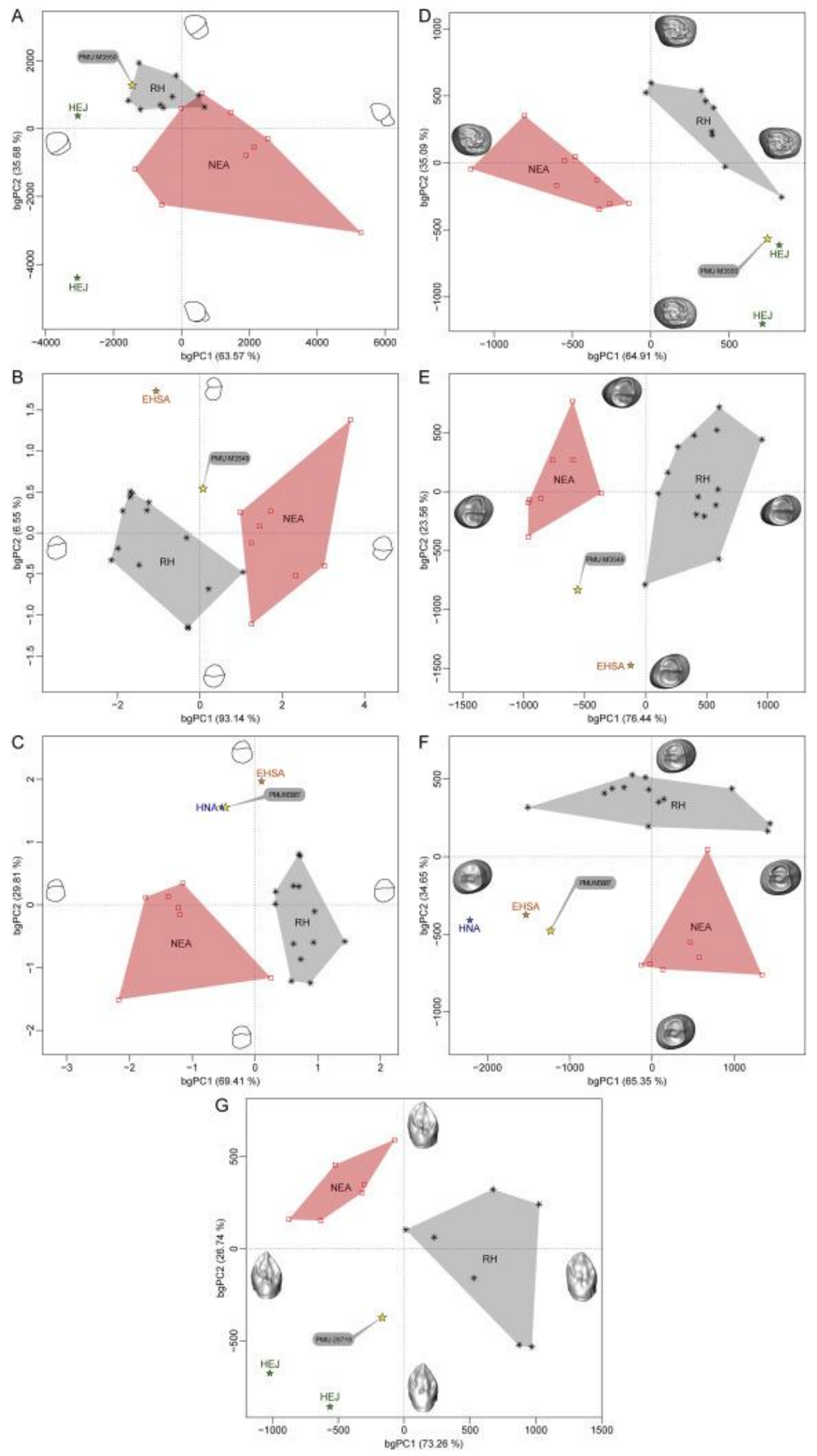
Figure 6. Between-group principal component analysis (bgPCA) of the enamel-dentine junction (EDJ) of the four Homo erectus specimens from Zhoukoudian (PMU 25719, UC; PMU M3550, UM3; PMU M3549, LP3; PMU M3887, LP4) compared to some fossil and extant human specimens/samples (details in Table 2). (A) Semilandmarks based analysis of the UM3s. (B) Semilandmarks based analysis of the LP3s. (C) Semilandmarks based analysis of the LP4. (D) Deformation based analysis of the UM3s. (E) Deformation based analysis of the LP3s. (F) Deformation based analysis of the LP4s. (G) Deformation based analysis of the UCs. The ridge curves and surfaces illustrate the extreme shapes along each bgPC for the semilandmark analyses. EHSA = early Homo from South Africa (SKX 21204 from Swartkrans), HEJ = Homo erectus from Java (NG0802.1 and Sangiran 4 from Sangiran), HNA = late Early-early Middle Pleistocene Homo from North Africa (Tighenif 2), NEA = Neanderthals (Krapina), $\mathrm{RH}=$ recent humans.

Table 2. Fossil and extant human specimens/samples used in the geometric morphometric (GM) analyses of the enamel-dentine junction (EDJ).

\begin{tabular}{|c|c|c|c|c|c|c|}
\hline Specimen/sample & Site & $\mathbf{U C}$ & UM3 & LP3 & LP4 & References \\
\hline H. erectus from & Locality 1 & PMU & PMU M3550 & PMU & PMU & Present \\
\hline Zhoukoudian & & 25719 & & M3549 & M3887 & study \\
\hline H. erectus from & Sangiran & Sangiran 4 & NG0802.1, & & & Zanolli, \\
\hline \multirow[t]{7}{*}{ Java (HEJ) } & Dome & & Sangiran 4 & & & 2011 \\
\hline & & & & & & Zanolli, \\
\hline & & & & & & 2013 \\
\hline & & & & & & Zanolli, \\
\hline & & & & & & 2015 \\
\hline & & & & & & Original \\
\hline & & & & & & data \\
\hline Early Homo from & Swartkrans & & & SKX & SKX & Pan et al., \\
\hline South Africa & & & & 21204 & 21204 & 2016 \\
\hline (EHSA) & & & & & & \\
\hline
\end{tabular}




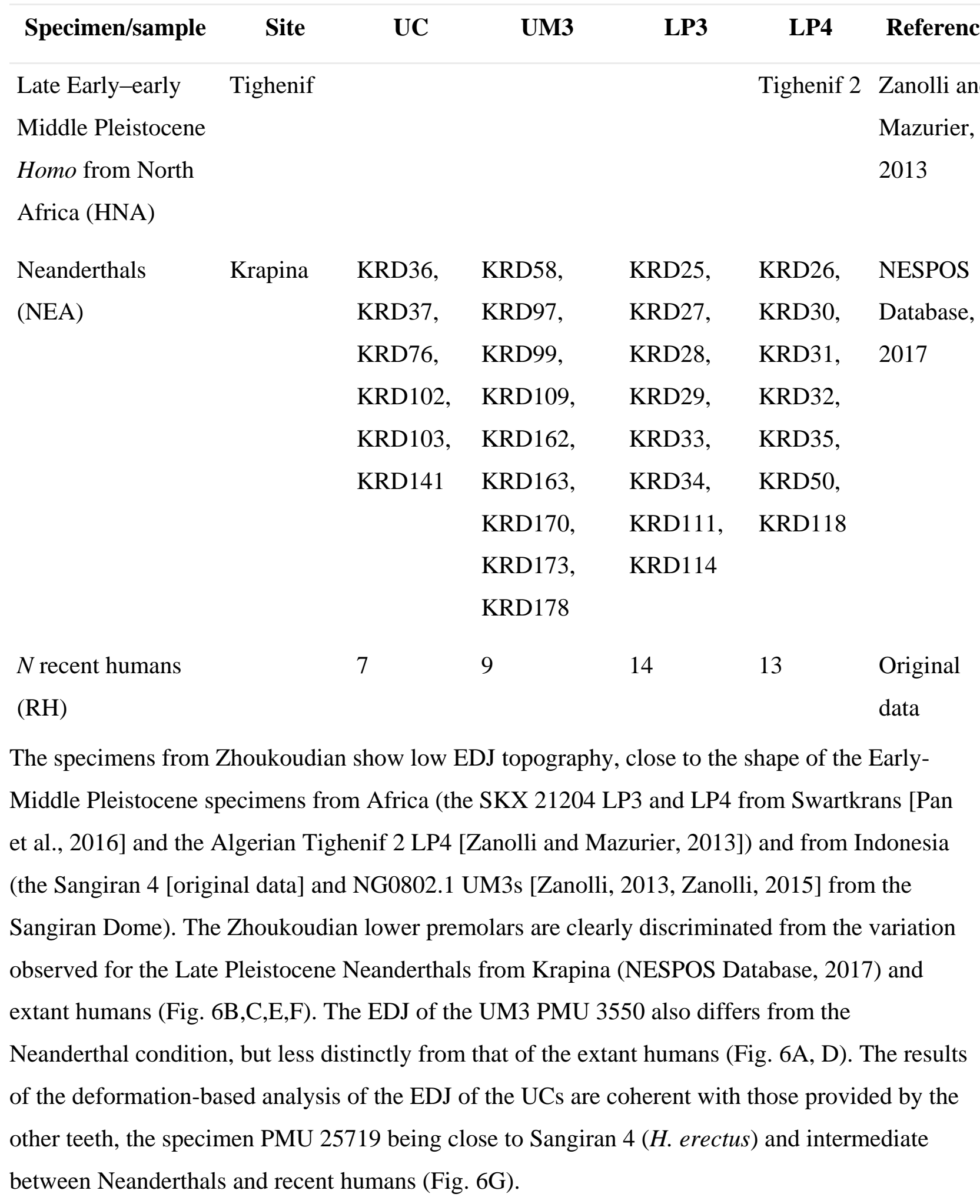

\section{Discussion and conclusions}

Recent studies of the Early and Middle Pleistocene hominin dental record from continental Asia, including the remains from the Chinese sites of Chaoxian, Jianshi, Hexian, Panxian Dadong, 
Yiyuan, Zhoukoudian (e.g., Xing et al., 2009, Xing et al., 2014, Xing et al., 2016, Bailey and Liu, 2010, Liu et al., 2010, Liu et al., 2013, Liu et al., 2017), and from insular Southeast Asia, such as the Indonesian assemblage from the Sangiran Dome (Kaifu et al., 2005a, Kaifu et al., 2005b, Kaifu, 2006, Zaim et al., 2011, Zanolli, 2011, Zanolli, 2013, Zanolli, 2015, Zanolli et al., 2012), show a wide range of morpho-dimensional variability through time and space (Martinón-Torres et al., 2017). For the Middle Pleistocene, this can be exemplified by the contrast at a regional scale between the small human mandible SOA-MM4 from Mata Menge, Flores Island, suggesting a body size similar to the Late Pleistocene hominins from Liang Bua (van den Bergh et al., 2016), and the robust mandible Penghu 1 from Taiwan, showing a thick corpus and large teeth (Chang et al., 2015).

In such a contrasted scenario likely resulting from complex population dynamics (Qiu, 2016), "characterising the morphology and spatio-temporal distribution of the Asian hominins would be a critical contribution to the current debate about the pattern of hominin settlement in Asia" (Martinón-Torres et al., 2017:2). Thus, despite their modest quantity, there is potential interest in the signal extracted from the inner structure of the four tooth specimens from Zhoukoudian Locality 1 for tentatively exploring some evolutionary trends.

Studies focusing on molar crown tissue proportions show that most fossil and extant PlioPleistocene hominins share absolutely and relatively thick enamel (Smith et al., 2012, Zanolli and Mazurier, 2013, Skinner et al., 2015, Zanolli, 2015, Pan et al., 2016), apart from the relatively thinly enameled Neanderthals (Macchiarelli et al., 2006, Macchiarelli et al., 2013, Olejniczak et al., 2008a) and for the condition of some isolated specimens (e.g., Zanolli et al., 2014). This does not, however, concern the still poorly explored existence of taxon/population-specific patterns in enamel thickness topographic distribution (Zanolli et al., 2017).

Within the limited amount of directly comparable evidence, both the LP3 PMU M3549 and the UM3 PMU M3550 from Zhoukoudian (this latter specimen uniquely assessed for its lateral enamel) are thickly enameled to an extent similar to the condition assessed in a penecontemporaneous upper M2 (PA833) from Longtan Cave, Hexian (2D RET: 23.5; Xing et al., 2014). These estimates also align with those obtained on six $H$. erectus molars from Java (average 3D RET: 21.9; Zanolli, 2015). In this respect, no obvious distinction is currently possible among the tooth assemblages from continental and island Southeast Asia. 
As shown in previous studies, the analysis of the EDJ shape rather distinctly discriminates among, and even within, hominin taxa (e.g., Skinner et al., 2008b, Crevecoeur et al., 2014, Zanolli et al., 2014, Martin et al., 2017). All Middle Pleistocene Chinese upper molars from Yiyuan, Hexian, and Zhoukoudian investigated so far (Xing et al., 2014, Xing et al., 2016; this study) resemble the primitive condition expressed in this study by the Early Pleistocene Sangiran 4 molars (Fig. 7). Specifically, they share: dense occlusal wrinkling; a relatively low EDJ topography with numerous secondary ridges and grooves; marked distal displacement of the lingual essential segment of the oblique crest (i.e., instead of running buccolingually from the protocone dentine horn, the oblique crest initiates about $2 \mathrm{~mm}$ distally, from the lingual marginal ridge); and a proportionally much larger trigon than talon basin (Fig. 7). The lower molars from the same Chinese localities also show a densely crenulated occlusal morphology of the EDJ, with a low topography and accessory traits (Xing et al., 2016, Liu et al., 2017). Conversely, the late Early to early Middle Pleistocene Indonesian mandibular specimens from the Kabuh Formation of the Sangiran Dome (Zanolli et al., 2012, Zanolli, 2015) reveal a slightly derived, simplified structural pattern consisting of; mesiodistal reduction, reduction or even loss of the hypoconulid and hypocone, and higher and less crenulated EDJ reliefs (Fig. 7). 


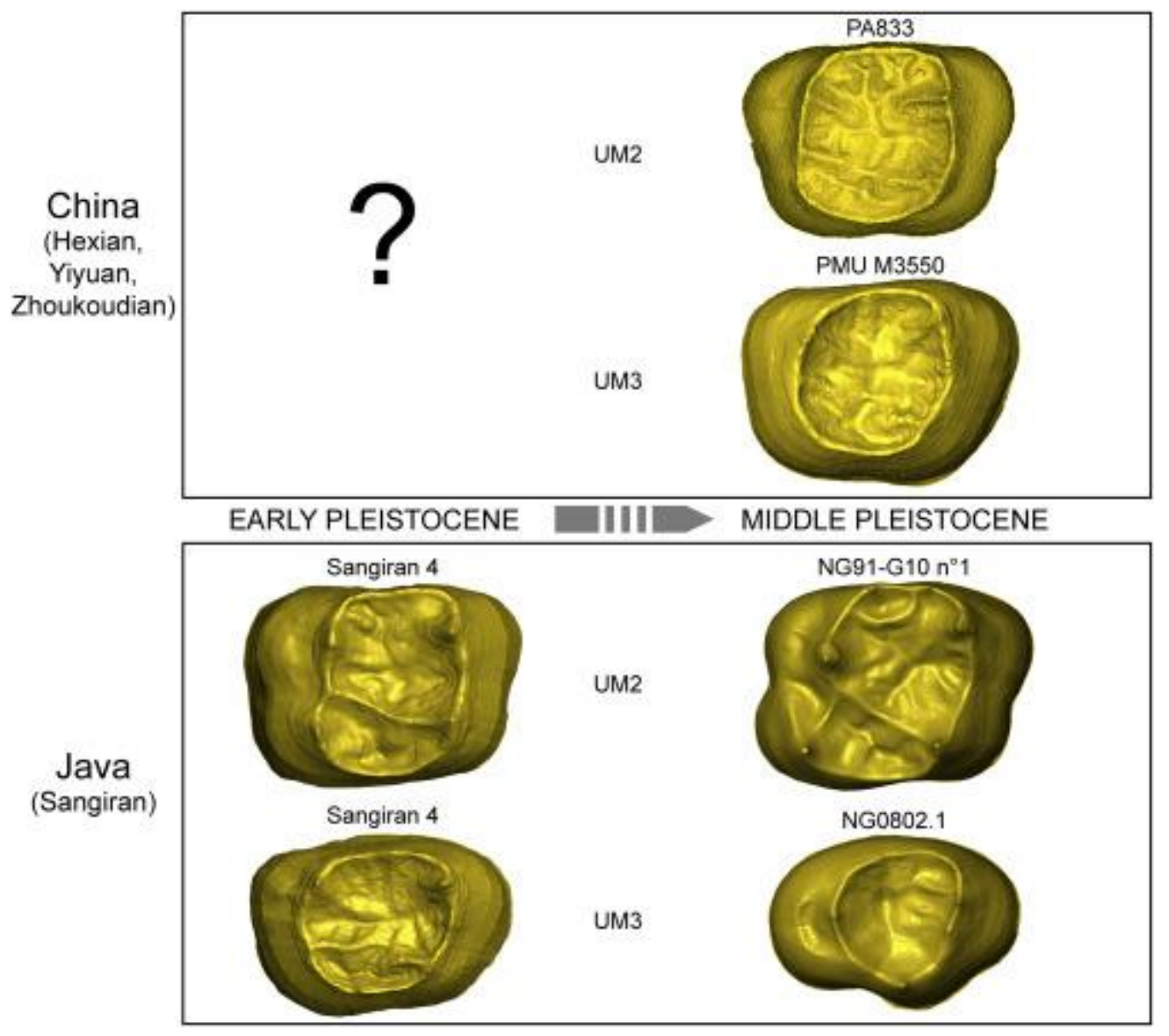

Figure 7. Schematic representation of the possible time-related evolutionary trajectories of the enamel-dentine junction (EDJ) conformation in Indonesian Homo erectus upper molars as exemplified by the condition displayed by tooth specimens from Sangiran, Java (lower panel; Zanolli, 2015; this study). The endostructural condition in Early Pleistocene Chinese molar crowns is currently unknown, however, the H. erectus specimens from Hexian, Yiyuan, and Zhoukoudian (Xing et al., 2014; this study) reveal a pattern closer to that of the earlier, not of the later, Indonesian representatives (upper panel; see also Fig. $6)$.

Different from the results of enamel thickness, the analysis of the EDJ suggests the existence of time-related endostructural differences between the continental and insular Southeast Asian dental assemblages available so far. The Middle Pleistocene Chinese tooth crowns would apparently retain a signal closer to the likely primitive model, here exemplified by the Early Pleistocene Sangiran 4 specimen, while the pattern expressed by their penecontemporaneous Indonesian representatives points to EDJ structural simplification (Zanolli, 2015, van den Bergh 
et al., 2016). Interestingly, a simplified condition (revealed by the loss of the hypoconulid in the lower molars, the absence/reduction of accessory crests, protostylid and accessory cusp expression) also characterizes the inner molar morphology of the Late Pleistocene Flores hominins (Kaifu et al., 2015), even if it has been recently reiterated that a close phylogenetic relationship between Homo floresiensis and H. erectus is not a foregone conclusion (Argue et al., 2017; but see; Felizola Diniz-Filho and Raia, 2017).

As demonstrated by the dental remains from Panxian Dadong, Southern China, and Xujiayao, Northern China, complex features are retained at the EDJ until the Late Pleistocene (e.g., a welldeveloped tuberculum dentale with finger-like extensions on lingual aspect of the anterior teeth, elevated and thick distal crest on the canine, asymmetrical lower P3 crown contour accessory crests, low dentine topography with numerous accessory crests and cusps, Liu et al., 2013, Xing et al., 2015). While such archaic-like conditions persisted late in China, the appearance in continental Eastern Asia of a derived endostructural molar tooth pattern does not seem to precede the second half of the Middle Pleistocene.

Tooth-based information is still quantitatively too scarce and widely spread to allow reliable reconstructions of the evolutionary dynamics of Early and Middle Pleistocene human groups across continental and insular Southeast Asia. Current models oscillate between a virtually continuous occupation of the macro-region all along the Pleistocene, to peopling patterns implying much more sporadic and localized settlements (review in Martinón-Torres et al., 2017). Whatever the most likely scenario may be, one should keep in mind the role eustatic- and tectonic-related events had on the peopling phases and evolutionary dynamics of hominin populations, having intermittently connected/isolated the Sunda region to the Asian mainland (e.g., Voris, 2000, de Vos and Long, 2001, van den Geer et al., 2010, Larick and Ciochon, 2015). Another relevant aspect to consider concerns the role of buffer/filter in continental Southeast Asia played by the persistence of a relatively stable humid and dense rainforest environment through most of the Pleistocene (Ciochon, 2009, Ciochon, 2010). Once set within a robust chronological framework, the integration of such ecological determinants would help in assessing the processes leading to the early establishment of the differences in outer and inner tooth crown morphology between the Indonesian and the Chinese dental assemblages outlined in this study (Kaifu et al., 2005a, Bailey and Liu, 2010, Liu et al., 2013, Liu et al., 2017, Zanolli, 2013, Xing et al., 2014, Xing et al., 2016, Kundrát et al., 2015; present study), the retention in the early Middle 
Pleistocene Chinese sample of archaic dental features (Xing et al., 2014, Xing et al., 2016, Kundrát et al., 2015, Liu et al., 2017; present study), and the peculiar morphology of the Northern Asian teeth (including highly complex occlusal morphology) not seen so far in any other human fossil sample (Xing et al., 2014, Xing et al., 2016).

We conclude that only a subtle revision of previously collected remains and the discovery and analysis of new dental material from reasonably well-constrained chronological contexts will allow appropriate testing of the suggested and alternative scenarios.

\section{Acknowledgments}

We thank F. Bernardini for help in the elaboration of the microtomographic record of the Zhoukoudian material at the Multidisciplinary Laboratory of the International Centre for Theoretical Physics (in the frame of the EXACT Project funded by the Regione Friuli-Venezia Giulia). We are grateful to B. Kear and J.O. Ebbestad for access to the fossil specimens housed at the Museum of Evolution of Uppsala University. For access to the fossil specimens stored at the Balai Pelestarian Situs Manusia Purba of Sangiran, we are indebted to H. Widianto and also acknowledge F. Sémah and D. Grimaud-Hervé. We thank S. Potze for access to the specimen SKX 21204, as well as F. de Beer, J. Braga, and J.W. Hoffman for sharing its $\mu$ CT record. For access to additional comparative material stored at the MNHN of Paris and at the University. of Poitiers, we thank C. Argot, D. Bouchon, C. Braquard, A. Fort, A. Froment, and P. Mennecier, as well as A. Mazurier for analytical support at the Centre de Microtomographie set at the University of Poitiers. This work granted access to the HPC resources of CALMIP supercomputing center under the allocation 2016-[P1440] attributed to the AMIS Laboratory, Toulouse. For scientific discussion and comments, we are also grateful to S.E. Bailey, Y. Kaifu, and M. Martinón-Torres. The present version greatly benefited from comments provided by two reviewer and the Associate Editor. Research supported by the French INEE-CNRS, the ICTP of Trieste, and the Chinese KLP-CAS (No. 173119).

\section{References}

Antón, 2003

S.C. Antón

\section{Natural history of Homo erectus}


Yearb. Phys. Anthropol., 46 (2003), pp. 126-170

Antón, 2013

S.C. Antón

Homo erectus and related taxa

D.R. Begun (Ed.), A Companion to Paleoanthropology, Blackwell Publishing Ltd., Pondicherry (2013), pp. 497-516

Argue et al., 2017

D. Argue, C.P. Groves, M.S.Y. Lee, W.L. Jungers

The affinities of Homo floresiensis based on phylogenetic analyses of cranial, dental, and postcranial characters

J. Hum. Evol., 107 (2017), pp. 107-133

Baddeley et al., 2015

A. Baddeley, E. Rubak, R. Turner

Spatial Point Patterns: Methodology and Applications with R

Chapman and Hall/CRC Press, London (2015)

Bailey and Liu, 2010

S.E. Bailey, W. Liu

A comparative dental metrical and morphological analysis of a Middle Pleistocene hominin maxilla from Chaoxian (Chaohu), China

Quatern. Intl., 211 (2010), pp. 14-23

Bailey et al., 2011

S.E. Bailey, M.M. Skinner, J.J. Hublin

What lies beneath? An evaluation of lower molar trigonid crest patterns based on both dentine and enamel expression

Am. J. Phys. Anthropol., 145 (2011), pp. 505-518 
Bayle et al., 2010

P. Bayle, R. Macchiarelli, E. Trinkaus, C. Duarte, A. Mazurier, J. Zilhão

Dental maturational pattern and dental tissue proportions in the early Upper Paleolithic child from Abrigo do Lagar Velho, Portugal

Proc. Natl. Acad. Sci., 107 (2010), pp. 1338-1342

Beaudet et al., 2016

A. Beaudet, J. Dumoncel, J.F. Thackeray, L. Bruxelles, L. Duployer, C. Tenailleau, L. Bam, J. Hoffman, F. de Beer, J. Braga

Upper third molar internal structural organization and semicircular canal morphology in Plio-Pleistocene South African cercopithecoids

J. Hum. Evol., 95 (2016), pp. 104-120

Benazzi et al., 2013a

S. Benazzi, H.N. Nguyen, O. Kullmer, J.J. Hublin

Unravelling the functional biomechanics of dental features and tooth wear

PLoS One, 8 (2013), p. e69990, 10.1371/journal.pone.0069990

Benazzi et al., 2013b

S. Benazzi, H.N. Nguyen, D. Schulz, I.R. Grosse, G. Gruppioni, J.J. Hublin, O. Kullmer

The evolutionary paradox of tooth wear: simply destruction or inevitable adaptation?

PLoS One, 8 (2013), p. e62263, 10.1371/journal.pone.0062263

Berger et al., 2012

L.R. Berger, L. Wu, X. Wu

Investigation of a credible report by a US Marine on the location of the missing Peking Man fossils

S. Afr. J. Sci., 108 (3/4) (2012), 10.4102/sajs.v108i3/4.1122

Binford and Ho, 1985

L.R. Binford, C.H. Ho 
Taphonomy at a distance: Zhoukoudian, "the cave home of Beijing man?"

Curr. Anthropol., 26 (1985), pp. 413-442

Black, 1927

D. Black

The lower molar hominid tooth from the Chou Kou Tien deposit

Palaeontol. Sin. D, 7 (1927), pp. 1-29

Black, 1933

D. Black

Fossil Man in China. The Choukoutien Cave deposits with a synopsis of our present knowledge of the Late Cenozoic in China

Mem. Geol. Surv. China A, 11 (1933), pp. 1-166

Black, 1934

D. Black

On the discovery, morphology and environment of Sinanthropus pekinensis

Phil. Trans. R. Soc. Lond. B, 223 (1934), pp. 57-120

Black et al., 1933

D. Black, S.J. Teilhard de Chardin, C.C. Young, W.C. Pei, W.W. Hao

Fossil man in China. The Choukoutien cave deposits with a synopsis of our present knowledge of the Late Cenozoic in China

Geol. Mem., 11 (1933), pp. 1-166

Boaz et al., 2000

N.T. Boaz, R.L. Ciochon, Q. Xu, J. Liu

Large mammalian carnivores as a taphonomic factor in the bone accumulation at Zhoukoudian

Acta Anthropol. Sin., 19 (2000), pp. 224-234 
Boaz et al., 2004

N.T. Boaz, R.L. Ciochon, Q. Xu, J. Liu

Mapping and taphonomic analysis of the Homo erectus loci at Locality 1 Zhoukoudian, China

J. Hum. Evol., 46 (2004), pp. 519-549

Bondioli et al., 2010

L. Bondioli, P. Bayle, C. Dean, A. Mazurier, L. Puymerail, C. Ruff, J.T. Stock, V. Volpato, C.

Zanolli, R. Macchiarelli

Morphometric maps of long bone shafts and dental roots for imaging topographic thickness variation

Am. J. Phys. Anthropol., 142 (2010), pp. 328-334

Bookstein, 1991

F.L. Bookstein

Morphometric tools for landmark data: Geometry and biology

Cambridge University Press, Cambridge (1991)

Chang et al., 2015

C.H. Chang, Y. Kaifu, M. Takai, R.T. Kono, R. Grün, S. Matsúura, L. Kinsley, L.K. Lin

The first archaic Homo from Taiwan

Nat. Commun., 6 (2015), p. 6037, 10.1038/ncomms7037

Ciochon, 2009

R.L. Ciochon

The mystery ape of Pleistocene Asia

Nature, 459 (2009), pp. 910-911

Ciochon, 2010

R.L. Ciochon 
Divorcing hominins from the Stegodon-Ailuropoda fauna: new views on the antiquity of hominins in Asia

J.G. Fleagle, J.J. Shea, F.E. Grine, A.L. Baden, R.E. Leakey (Eds.), Out of Africa I: The First Hominin Colonization of Eurasia, Springer, Dordrecht (2010), pp. 111-126

Ciochon et al., 2000

R.L. Ciochon, N.T. Boaz, Q. Xu, G. Liu

Hominin bone accumulation at Zhoukoudian: the role of large carnivores

Am. J. Phys. Anthropol., 30 (2000), p. 125

(Abstract)

Coleman and Colbert, 2007

M.N. Coleman, M.W. Colbert

Technical note: CT thresholding protocols for taking measurements on three-dimensional models

Am. J. Phys. Anthropol., 133 (2007), pp. 723-725

Crevecoeur et al., 2014

I. Crevecoeur, M.M. Skinner, S.E. Bailey, P. Gunz, S. Bortoluzzi, A.S. Brooks, C. Burlet, E. Cornelissen, N. De Clerck, B. Maureille, P. Semal, Y. Vanbrabant, B.A. Wood First early hominin from Central Africa (Ishango, Democratic Republic of Congo) PLoS One, 9 (2014), p. e84652, 10.1371/journal.pone.0084652

de Vos and Long, 2001

J. de Vos, V.T. Long

First settlements: relation between continental and insular Southeast Asia

A.M. Sémah, F. Sémah, C. Falguères, D. Grimaud-Hervé (Eds.), Origine des Peuplements et Chronologie des Cultures Paléolithiques dans le Sud-Est Asiatique, Artcom', Paris (2001), pp. 331-358

Dumoncel et al., 2014 
J. Dumoncel, S. Durrleman, J. Braga, J.-P. Jessel, G. Subsol

Landmark-free 3D method for comparison of fossil hominins and hominids based on endocranium and EDJ shapes

Am. J. Phys. Anthropol., 153 (2014), p. 110

(Abstract)

Durrleman et al., 2012a

S. Durrleman, X. Pennec, A. Trouvé, N. Ayache, J. Braga

Comparison of the endocranial ontogenies between chimpanzees and bonobos via temporal regression and spatiotemporal registration

J. Hum. Evol., 62 (2012), pp. 74-88

Durrleman et al., 2012b

S. Durrleman, M. Prastawa, J.R. Korenberg, S. Joshi, A. Trouvé, G. Gerig

Topology preserving atlas construction from shape data without correspondence using sparse parameters

N. Ayache, H. Delingette, P. Golland, K. Mori (Eds.), Proceedings of Medical Image Computing and Computer Aided Intervention. Nice, France (2012), pp. 223-230

Durrleman et al., 2014

S. Durrleman, M. Prastawa, N. Charon, J.R. Korenberg, S. Joshi, G. Gerig, A. Trouvé Morphometry of anatomical shape complexes with dense deformations and sparse parameters

NeuroImage, 101 (2014), pp. 35-49

Fajardo et al., 2002

R.J. Fajardo, T.M. Ryan, J. Kappelman

Assessing the accuracy of high resolution X-ray computed tomography of primate trabecular bone by comparisons with histological sections

Am. J. Phys. Anthropol., 118 (2002), pp. 1-10 
Felizola Diniz-Filho and Raia, 2017

J.A. Felizola Diniz-Filho, P. Raia

Island rule, quantitative genetics and brain-body size evolution in Homo floresiensis

Proc. R. Soc. B, 284 (2017), p. 20171065

Gaboardi et al., 2005

M. Gaboardi, T. Deng, Y. Wang

Middle Pleistocene climate and habitat change at Zhoukoudian, China, from the carbon and oxygen isotopic record from herbivore tooth enamel

Quatern. Res., 63 (2005), pp. 329-338

Glaunès and Joshi, 2006

J.A. Glaunès, S. Joshi

Template estimation from unlabeled point set data and surfaces for computational anatomy

X. Pennec, S. Joshi (Eds.), Proceedings of the International Workshop on the Mathematical

Foundations of Computational Anatomy. Copenhagen, Denmark (2006), pp. 29-39

Goldberg et al., 2001

P. Goldberg, S. Weiner, O. Bar-Yosef, Q.Q. Xu, J.Y. Liu

Site formation processes at Zhoukoudian, China

J. Hum. Evol., 41 (2001), pp. 483-530

Grün et al., 1997

R. Grün, P.H. Huang, X. Wu, C.B. Stringer, A.G. Thorne, M. McCulloch

ESR analysis of teeth from the palaeoanthropological site of Zhoukoudian, China

J. Hum. Evol., 32 (1997), pp. 83-91

Guo et al., 1991

S.L. Guo, S.S. Liu, S.F. Sun, F. Zhang, S.H. Zhou, X.H. Hao, W. Meng, F. Zhang, J.F. Liu

Fission track dating of the 4th Layer of the Peking Man Site

Acta Anthropol. Sin., 10 (1991), pp. 73-77 
Guy et al., 2013

F. Guy, F. Gouvard, R. Boistel, A. Euriat, V. Lazzari

Prospective in (Primate) dental analysis through tooth 3D topographical quantification

PLoS One, 8 (2013), p. e66142, 10.1371/journal.pone.0066142

Hu, 1985

C. $\mathrm{Hu}$

The history of mammalian fauna of locality 1 of Zhoukoudian and its recent advances

R.K. Wu, M. Ren, X. Zhu (Eds.), Multi-disciplinary Study of the Peking Man Site at Zhoukoudian, Science Press, Beijing (1985), pp. 107-113

Huang et al., 1993

P.H. Huang, S.Z. Jin, Z.C. Peng, R.Y. Liang, Z.J. Lu, Z.R. Wang, J.B. Chen, Z.X. Yuan

ESR dating of tooth enamel: comparison with U-Series, FT and TL dating at the Peking Man Site

Appl. Radiat. Isot., 44 (1993), pp. 239-242

Kaifu, 2006

Y. Kaifu

Advanced dental reduction in Javanese Homo erectus

Anthropol. Sci., 114 (2006), pp. 35-43

Kaifu et al., 2005a

Y. Kaifu, F. Aziz, H. Baba

Hominid mandibular remains from Sangiran: 1952-1986 collection

Am. J. Phys. Anthropol., 128 (2005), pp. 497-519

Kaifu et al., 2005b

Y. Kaifu, H. Baba, F. Aziz, E. Indriati, F. Schrenk, T. Jacob 
Taxonomic affinities and evolutionary history of the Early Pleistocene hominids of Java: dentognathic evidence

Am. J. Phys. Anthropol., 128 (2005), pp. 709-726

Kaifu et al., 2015

Y. Kaifu, R.T. Kono, T. Sutikna, E.W. Saptomo, Jatmiko, R. Due Awe

Unique dental morphology of Homo floresiensis and its evolutionary implications

PLoS One, 10 (2015), p. e0141614, 10.1371/journal.pone.0141614

Kono, 2004

R. Kono

Molar enamel thickness and distribution patterns in extant great apes and humans: new insights based on a 3-dimensional whole crown perspective

Anthropol. Sci., 112 (2004), pp. 121-146

Kono and Suwa, 2008

R. Kono, G. Suwa

Enamel distribution patterns of extant human and hominoid molars: occlusal versus lateral enamel thickness

Bull. Natl. Mus. Nat. Sci. Ser. D, 34 (2008), pp. 1-9

Kundrát et al., 2015

M. Kundrát, W. Liu, J.O. Ebbestad, P. Ahlberg, H. Tong

New tooth of Peking Man recognized in laboratory at Uppsala University

Acta Anthropol. Sin., 34 (2015), pp. 131-136

Kupczik and Hublin, 2010

K. Kupczik, J.J. Hublin

Mandibular molar root morphology in Neanderthals and Late Pleistocene and recent Homo sapiens

J. Hum. Evol., 59 (2010), pp. 525-541 
Larick and Ciochon, 2015

R. Larick, R.L. Ciochon

Early hominin biogeography in Island Southeast Asia

Evol. Anthropol., 24 (2015), pp. 185-213

Li, 2016

F. Li

An experimental study of bipolar reduction at Zhoukoudian locality 1, north China

Quatern. Intl., 400 (2016), pp. 23-29

Li et al., 2014

Y. Li, Y. Zhang, X. Wu, H. Ao, L. Li, Z. An

Mammalian evolution in Asia linked to climate changes

Z. An (Ed.), Late Cenozoic Climate Change in Asia. Loess, Monsoon and Monsoon-arid Environment Evolution, Springer, Dordrecht (2014), pp. 435-490

Lin, 1985

S.L. Lin

Large fossil mammals of locality 1 of Zhoukoudian and the hunting behavior of Peking man

R.K. Wu, M. Ren, X. Zhu (Eds.), Multi-disciplinary Study of the Peking Man Site at

Zhoukoudian, Science Press, Beijing (1985), pp. 95-101

Liu et al., 2010

W. Liu, R. Clarke, S. Xing

Geometric morphometric analysis of the early Pleistocene hominin teeth from Jianshi, Hubei Province, China

Sci. China Earth Sci., 53 (2010), pp. 1141-1152

Liu et al., 2013

W. Liu, L.A. Schepartz, S. Xing, S. Miller-Antonio, X. Wu, E. Trinkaus, M. Martinón-Torres 


\section{Late Middle Pleistocene hominin teeth from Panxian Dadong, South China}

J. Hum. Evol., 64 (2013), pp. 337-355

Liu et al., 2017

W. Liu, M. Martinón-Torres, Y. Kaifu, X. Wu, R.T. Kono, C.H. Chang, P. Wei, S. Xing, W.

Huang, J.M. Bermúdez de Castro

A mandible from the Middle Pleistocene Hexian site and its significance in relation to the variability of Asian Homo erectus

Am. J. Phys. Anthropol., 162 (2017), pp. 715-731

Lucas, 2001

S.G. Lucas

\section{Pleistocene}

S.G. Lucas (Ed.), Chinese Fossil Vertebrates, Columbia University Press, New York (2001), pp. 259-289

Macchiarelli et al., 2006

R. Macchiarelli, L. Bondioli, A. Debénath, A. Mazurier, J.-F. Tournepiche, W. Birch, C. Dean How Neanderthal molar teeth grew

Nature, 444 (2006), pp. 748-751

Macchiarelli et al., 2008

R. Macchiarelli, L. Bondioli, A. Mazurier

Virtual dentitions: touching the hidden evidence

J.D. Irish, G.C. Nelson (Eds.), Technique and Application in Dental Anthropology, Cambridge University Press, Cambridge (2008), pp. 426-448

Macchiarelli et al., 2013

R. Macchiarelli, P. Bayle, L. Bondioli, A. Mazurier, C. Zanolli

From outer to inner structural morphology in dental anthropology. The integration of the third dimension in the visualization and quantitative analysis of fossil remains 
R.G. Scott, J.D. Irish (Eds.), Anthropological Perspectives on Tooth Morphology: Genetics, Evolution, Variation, Cambridge University Press, Cambridge (2013), pp. 250-277

Martin et al., 2017

M.R.G. Martin, J.-J. Hublin, P. Gunz, M.M. Skinner

The morphology of the enamel-dentine junction in Neanderthal molars: gross morphology, non-metric traits, and temporal trends

J. Hum. Evol., 103 (2017), pp. 20-44

Martínez de Pinillos et al., 2014

M. Martínez de Pinillos, M. Martinón-Torres, M.M. Skinner, J.L. Arsuaga, A. Gracia-Téllez, I. Martínez, L. Martín-Francés, J.M. Bermúdez de Castro

Trigonid crests expression in Atapuerca-Sima de los Huesos lower molars: internal and external morphological expression and evolutionary inferences

C.R. Palevol., 13 (2014), pp. 205-221

Martinón-Torres et al., 2014

M. Martinón-Torres, M. Martínez de Pinillos, M.M. Skinner, L. Martín-Francés, A. Gracia-

Téllez, I. Martínez, J.L. Arsuaga, J.M. Bermúdez de Castro

Talonid crests expression at the enamel-dentine junction of hominin lower permanent and deciduous molars

C.R. Palevol., 13 (2014), pp. 223-234

Martinón-Torres et al., 2017

M. Martinón-Torres, S. Xing, W. Liu, J.M. Bermúdez de Castro

A "source and sink" model for East Asia? Preliminary approach through the dental evidence

C.R. Palevol (2017), 10.1016/j.crpv.2015.09.011 (in press)

Mitteroecker and Bookstein, 2011

P. Mitteroecker, F.L. Bookstein 
Linear discrimination, ordination, and the visualization of selection gradients in modern morphometrics

Evol. Biol., 38 (2011), pp. 100-114

Mitteroecker et al., 2013

P. Mitteroecker, P. Gunz, S. Windhager, K. Schaefer

A brief review of shape, form, and allometry in geometric morphometrics, with applications

to human facial morphology

Hystrix, 24 (2013), pp. 59-66

NESPOS Database, 2017

NESPOS Database

NEanderthal Studies Professional Online Service

(2017)

http://www.nespos.org

Olejniczak et al., 2008a

A.J. Olejniczak, T.M. Smith, R.N.M. Feeney, R. Macchiarelli, A. Mazurier, L. Bondioli, A.

Rosas, J. Fortea, M. de la Rasilla, A. Garcia-Tabernero, J. Radovčić, M.M. Skinner, M.

Toussaint, J.-J. Hublin

Dental tissue proportions and enamel thickness in Neandertal and modern human molars

J. Hum. Evol., 55 (2008), pp. 12-23

Olejniczak et al., 2008b

A.J. Olejniczak, T.M. Smith, M.M. Skinner, F.E. Grine, R.N.M. Feeney, J.F. Thackeray, J.-J. Hublin

Three-dimensional molar enamel distribution and thickness in Australopithecus and Paranthropus

Biol. Lett., 4 (2008), pp. 406-410

Ortiz et al., 2012 
A. Ortiz, M.M. Skinner, S.E. Bailey, J.-J. Hublin

Carabelli's trait revisited: an examination of mesiolingual features at the enamel-dentine junction and enamel surface of Pan and Homo sapiens upper molars

J. Hum. Evol., 63 (2012), pp. 586-596

Pan et al., 2016

L. Pan, J. Dumoncel, F. de Beer, J. Hoffman, J.F. Thackeray, B. Duployer, C. Tenailleau, J. Braga

Further morphological evidence on South African earliest Homo lower postcanine dentition: enamel thickness and enamel dentine junction

J. Hum. Evol., 96 (2016), pp. 82-96

Pan et al., 2017

L. Pan, J.F. Thackeray, J. Dumoncel, C. Zanolli, A. Oettlé, F. de Beer, J. Hoffman, B. Duployer, C. Tenailleau, J. Braga

Intra-individual metameric variation expressed at the enamel-dentine junction of lower post-canine dentition of South African fossil hominins and modern humans

Am. J. Phys. Anthropol., 163 (2017), pp. 806-815

Pebesma, 2004

E.J. Pebesma

Multivariable geostatistics in S: the gstat package

Comp. Geosci., 30 (2004), pp. 683-691

Pei, 1985

J. Pei

Thermoluminescence of the Peking Man site and other caves

R.K. Wu, M. Ren, X. Zhu (Eds.), Multi-disciplinary Study of the Peking Man Site at Zhoukoudian, Science Press, Beijing (1985), pp. 258-260

Pei and Zhang, 1985 
W. Pei, S. Zhang

A study on the lithic artifacts of Sinanthropus

Palaeontol. Sin. D, 12 (1985), pp. 1-277

Qiu, 2016

J. Qiu

The forgotten continent

Nature, 535 (2016), pp. 218-220

R Development Core Team, 2017

R Development Core Team

R: A Language and Environment for Statistical Computing (2017)

Available at: http://www.R-project.org

Rich et al., 1986

P.V. Rich, L.H. Hou, K. Ono, R.F. Baird

A review of the fossil birds of China, Japan and Southeast Asia

Geobios, 19 (1986), pp. 755-772

Schlager, 2017

S. Schlager

Morpho: Calculations and Visualizations Related to Geometric Morphometrics (2017)

$\mathrm{R}$ package version 2.5 .1

https://CRAN.R-project.org/package=Morpho

Schneider et al., 2012

C.A. Schneider, W.S. Rasband, K.W. Eliceiri

NIH Image to ImageJ: 25 years of image analysis

Nat. Methods, 9 (2012), pp. 671-675 
Schwartz and Tattersall, 2003

J.H. Schwartz, I. Tattersall

The Human Fossil Record

Craniodental Morphology of Genus Homo (Africa and Asia), vol. 2, Wiley-Liss, New York (2003)

Scott and Turner, 1997

G.R. Scott, C.G. Turner II

The Anthropology of Modern Human Teeth. Dental Morphology and its Variation in

Recent Human Populations

Cambridge University Press, Cambridge (1997)

Shen et al., 2016

C. Shen, X. Zhang, X. Gao

Zhoukoudian in transition: research history, lithic technologies, and transformation of

Chinese Palaeolithic archaeology

Quatern. Intl., 400 (2016), pp. 4-13

Shen et al., 2001

G.J. Shen, T.L. Ku, H. Cheng, R.L. Edwards, Z. Yuan, Q. Wang

High-precision U-series dating of Locality 1 at Zhoukoudian, China

J. Hum. Evol., 41 (2001), pp. 679-688

Shen et al., 2009

G.J. Shen, X. Gao, B. Gao, D.E. Granger

Age of Zhoukoudian Homo erectus determined with ${ }^{26} \mathrm{Al} /{ }^{10} \mathrm{Be}$ burial dating

Nature, 458 (2009), pp. 198-200

Skinner et al., 2008a

M.M. Skinner, B.A. Wood, C. Boesch, A.J. Olejniczak, A. Rosas, T.M. Smith, J.-J. Hublin 
Dental trait expression at the enamel-dentine junction of lower molars in extant and fossil hominoids

J. Hum. Evol., 54 (2008), pp. 173-186

Skinner et al., 2008b

M.M. Skinner, P. Gunz, B.A. Wood, J.-J. Hublin

Enamel-dentine junction (EDJ) morphology distinguishes the lower molars of

Australopithecus africanus and Paranthropus robustus

J. Hum. Evol., 55 (2008), pp. 979-988

Skinner et al., 2015

M.M. Skinner, Z. Alemseged, C. Gaunitz, J.-J. Hublin

Enamel thickness trends in Plio-Pleistocene hominin mandibular molars

J. Hum. Evol., 85 (2015), pp. 35-45

Smith, 1984

H.B. Smith

Patterns of molar wear in hunter-gatherers and agriculturalists

Am. J. Phys. Anthropol., 63 (1984), pp. 39-56

Smith et al., 2009

T.M. Smith, A.J. Olejniczak, K. Kupczik, V. Lazzari, J. de Vos, O. Kullmer, F. Schrenk, J.-J.

Hublin, T. Jacob, P. Tafforeau

Taxonomic assessment of the Trinil molars using nondestructive 3D structural and development analysis

PaleoAnthropology, 2009 (2009), pp. 117-129

Smith et al., 2012

T.M. Smith, A.J. Olejniczak, J.P. Zermeno, P. Tafforeau, M.M. Skinner, A. Hoffmann, J.

Radovčić, M. Toussaint, R. Kruszynski, C. Menter, J. Moggi-Cecchi, U.A. Glasmacher, O.

Kullmer, F. Schrenk, C. Stringer, J.-J. Hublin 
Variation in enamel thickness within the genus Homo

J. Hum. Evol., 62 (2012), pp. 395-411

Spoor et al., 1993

F. Spoor, F. Zonneveld, G.A. Macho

Linear measurements of cortical bone and dental enamel by computed tomography: applications and problems

Am. J. Phys. Anthropol., 91 (1993), pp. 469-484

Toussaint et al., 2010

M. Toussaint, A.J. Olejniczak, S. El Zaatari, P. Cattelain, D. Flas, C. Letourneux, S. Pirson The Neandertal lower right deciduous second molar from Trou de l'Abîme at Couvin, Belgium

J. Hum. Evol., 58 (2010), pp. 56-67

Tuniz et al., 2013

C. Tuniz, F. Bernardini, A. Cicuttin, M.L. Crespo, D. Dreossi, A. Gianoncelli, L. Mancini, A. Mendoza Cuevas, N. Sodini, G. Tromba, F. Zanini, C. Zanolli

The ICTP-Elettra X-ray laboratory for cultural heritage and archaeology. A facility for training and education in the developing world

Nucl. Instrum. Meth. A, 711 (2013), pp. 106-110

Turner et al., 1991

C.G. Turner II, C.R. Nichol, G.R. Scott

Scoring procedures for key morphological traits of the permanent dentition: the Arizona State University Dental Anthropology System

M.A. Kelley, C.S. Larsen (Eds.), Advances in Dental Anthropology, Wiley-Liss, New York (1991), pp. 13-31

van den Bergh et al., 2016 
G.D. van den Bergh, Y. Kaifu, I. Kurniawan, R.T. Kono, A. Brumm, E. Setiyabudi, F. Aziz, M.J. Morwood

Homo floresiensis-like fossils from the early Middle Pleistocene of Flores

Nature, 534 (2016), pp. 245-248

van den Geer et al., 2010

A.A.E. van den Geer, G. Lyras, J. de Vos, M. Dermitzakis

Evolution of Island Mammals. Adaptation and Extinction of Placental Mammals on Islands

Wiley-Blackwell, Chichester (2010)

Voris, 2000

H.K. Voris

Maps of Pleistocene sea levels in Southeast Asia: shorelines, river systems and time durations

J. Biogeogr., 27 (2000), pp. 1153-1167

Wang and Sun, 2000

Q. Wang, L. Sun

Eightieth year of Peking Man: current status of Peking Man and the Zhoukoudian site Anthropol. Rev., 63 (2000), pp. 19-30

Weidenreich, 1937

F. Weidenreich

The dentition of Sinanthropus pekinensis: a comparative odontography of the hominids

Palaeontol. Sin. D, 1 (1937), pp. 1-180

Weidenreich, 1941

F. Weidenreich

The extremity bones of Sinanthropus pekinensis

Palaeontol. Sin. D, 5 (1941), pp. 1-151 
Weidenreich, 1943

F. Weidenreich

The skull of Sinanthropus pekinensis. A comparative study on a primitive hominid skull Palaeontol. Sin. D, 10 (1943), pp. 1-484

Weiner et al., 1998

S. Weiner, Q. Xu, P. Goldberg, J. Liu, O. Bar-Yosef

Evidence for the use of fire at Zhoukoudian, China

Science, 281 (1998), pp. 251-253

Weiner et al., 1999

S. Weiner, Q. Xu, P. Goldberg, J. Liu, O. Bar-Yosef

Response to: investigating the possible use of fire at Zhoukoudian, China

Science, 283 (1999), p. 299a

Wood, 2011

B.A. Wood

Wiley-Blackwell Encyclopedia of Human Evolution

Wiley-Blackwell, Chichester (2011)

Wood, 2015

B.A. Wood

Wiley Blackwell Student Dictionary of Human Evolution

Wiley Blackwell, Chichester (2015)

Wu et al., 1985

R.K. Wu, M. Ren, X. Zhu

Multi-disciplinary Study of the Peking Man Site at Zhoukoudian

Science Press, Beijing (1985)

Wu, 1999 
$\mathrm{X} . \mathrm{Wu}$

Investigating the possible use of fire at Zhoukoudian, China

Science, 283 (1999), p. 299a

Xing et al., 2009

S. Xing, M. Zhou, W. Liu

Crown morphology and variation of the lower premolars of Zhoukoudian Homo erectus

Chin. Sci. Bull., 54 (2009), pp. 3905-3915

Xing et al., 2014

S. Xing, M. Martinón-Torres, J.M. Bermúdez de Castro, Y. Zhang, X. Fan, L. Zheng, W. Huang, W. Liu

Middle Pleistocene hominin teeth from Longtan Cave, Hexian, China

PLoS One, 9 (2014), p. e114265, 10.1371/journal.pone.0114265

Xing et al., 2015

S. Xing, M. Martinón-Torres, Bermúdez de Castro, X. Wu, W. Liu

Hominin teeth from the early Late Pleistocene site of Xujiayao, Northern China

Am. J. Phys. Anthropol., 156 (2015), pp. 224-240

Xing et al., 2016

S. Xing, C. Sun, M. Martinón-Torres, J.M. Bermúdez de Castro, F. Han, Y. Zhang, W. Liu

Hominin teeth from the Middle Pleistocene site of Yiyuan, Eastern China

J. Hum. Evol., 95 (2016), pp. 33-54

Yang et al., 1985

Z. Yang, Y. Mou, F. Qian, X. Wang, P. Niu, H. Chen, W. Yin, X. Wei

Study of the late Cenozoic strata at Zhoukoudian

R.K. Wu, M. Ren, X. Zhu (Eds.), Multi-disciplinary Study of the Peking Man Site at Zhoukoudian, Science Press, Beijing (1985), pp. 1-86 
Yuan and Chen, 1980

S.X. Yuan, T.N. Chen

Uranium-series dating of bones at Zhoukoudian

Acta Anthropol. Sin., 10 (1980), pp. 189-193

Zaim et al., 2011

Y. Zaim, R.L. Ciochon, J.M. Polanski, F.E. Grine, E.A. Bettis III, Y. Rizal, R.G. Franciscus, R.R.

Larick, M. Heizler, Aswan, K.L. Eaves, H.E. Marsh

New 1.5 million-year-old Homo erectus maxilla from Sangiran (Central Java, Indonesia)

J. Hum. Evol., 61 (2011), pp. 363-376

Zanolli, 2011

C. Zanolli

L'Organisation Endostructurale de Restes Dentaires Humains du Pléistocène Inférieur

Final-Moyen Initial d'Indonésie et d'Afrique, avec une Attention Particulière à Homo

erectus s.s. Caractérisation Comparative à Haute Résolution et Problématiques

Taxinomiques

Ph.D. Dissertation, Muséum National d'Histoire Naturelle, Paris

(2011)

Zanolli, 2013

C. Zanolli

Additional evidence for morpho-dimensional tooth crown variation in a new Indonesian $H$. erectus sample from the Sangiran Dome (Central Java)

PLoS One, 8 (2013), p. e67233, 10.1371/journal.pone.0067233

Zanolli, 2015

C. Zanolli

Molar crown inner structural organization in Javanese Homo erectus

Am. J. Phys. Anthropol., 156 (2015), pp. 148-157 
Zanolli and Mazurier, 2013

C. Zanolli, A. Mazurier

Endostructural characterization of the $H$. heidelbergensis dental remains from the early Middle Pleistocene site of Tighenif, Algeria

C.R. Palevol., 12 (2013), pp. 293-304

Zanolli et al., 2012

C. Zanolli, L. Bondioli, L. Mancini, A. Mazurier, H. Widianto, R. Macchiarelli

Two human fossil deciduous molars from the Sangiran Dome (Java, Indonesia): outer and inner morphology

Am. J. Phys. Anthropol., 147 (2012), pp. 472-481

Zanolli et al., 2014

C. Zanolli, L. Bondioli, A. Coppa, M.C. Dean, P. Bayle, F. Candilio, S. Capuani, D. Dreossi, I.

Fiore, D.W. Frayer, Y. Libsekal, L. Mancini, L. Rook, T. Medin Tekle, C. Tuniz, R. Macchiarelli

The late Early Pleistocene human dental remains from Uadi Aalad and Mulhuli-Amo

(Buia), Eritrean Danakil: macromorphology and microstructure

J. Hum. Evol., 74 (2014), pp. 96-113

Zanolli et al., 2015

C. Zanolli, F.E. Grine, O. Kullmer, F. Schrenk, R. Macchiarelli

The Early Pleistocene deciduous hominid molar FS-72 from the Sangiran Dome of Java, Indonesia: a taxonomic reappraisal based on its comparative endostructural characterization

Am. J. Phys. Anthropol., 157 (2015), pp. 666-674

Zanolli et al., 2017

C. Zanolli, P. Bayle, L. Bondioli, M.C. Dean, M. Le Luyer, A. Mazurier, W. Morita, R. Macchiarelli

Is the deciduous/permanent molar enamel thickness ratio a taxon-specific indicator in extant and extinct hominids? 
R. Macchiarelli, C. Zanolli (Eds.), Hominin Biomechanics, Virtual Anatomy and Inner Structural Morphology: From Head to Toe. A Tribute to Laurent Puymerail, C.R. Palevol., vol. 16 (2017), pp. $702-714$

Zdansky, 1926

O. Zdansky

Preliminary notice on two teeth of a hominid from a cave in Chihli (China)

Bull. Geol. Soc. China, 5 (1926), pp. 279-283

Zdansky, 1952

O. Zdansky

A new tooth of Sinanthropus pekinensis Black

Acta Zool., 33 (1952), pp. 189-191

Zhang et al., 2014

Y. Zhang, Z. Guo, C. Deng, S. Zhang, H. Wu, C. Zhang, J. Ge, D. Zhao, Q. Li, Y. Song, R. Zhu

The use of fire at Zhoukoudian: evidence from magnetic susceptibility and color measurements

Chin. Sci. Bull., 59 (2014), pp. 1013-1020

Zhao et al., 1985

S.S. Zhao, M. Xia, Z.H. Zhang, M.L. Liu, S.X. Wang, Q.F. Wu, Z.B. Ma

Uranium-series dating of the Peking Man Site

R.K. Wu, M. Ren, X. Zhu (Eds.), Multi-disciplinary Study of the Peking Man Site at Zhoukoudian, Science Press, Beijing (1985), pp. 246-250

Zhong et al., 2014

M. Zhong, C. Shi, X. Gao, X. Wu, F. Chen, S. Zhang, J.W. Olsen

On the possible use of fire by Homo erectus at Zhoukoudian, China

Chin. Sci. Bull., 59 (2014), pp. 335-343 
Zhou et al., 2000

C.L. Zhou, Z.C. Liu, Y.J. Wang, Q.H. Huang

Climatic cycles investigated by sediment analysis in Peking Man's cave, Zhoukoudian, China

J. Archaeol. Sci., 27 (2000), pp. 101-109 